\title{
Firm Dynamics, Job Turnover, and Wage Distributions in an Open Economy
}

(First draft)

\author{
A. Kerem Coşar, Nezih Guner and James Tybout ${ }^{1}$ \\ Pennsylvania State U., U. Carlos III de Madrid, and Pennsylvania State U. and NBER
}

June 10, 2009

\footnotetext{
${ }^{1}$ Without implicating them, we wish to thank John Haltiwanger, Marc Muendler, Nina Pavcnik and Andres Rodriguez-Clare for helpful discussions. This research was supported by the National Science Foundation (Grant No.SES-0617888). Any opinions, findings, and conclusions or recommendations expressed in this paper are those of the authors and do not necessarily reflect the views of the National Science Foundation.
} 


\begin{abstract}
As Latin American countries have become more open, their job turnover rates have risen, their informal sectors have become larger, and their wage distributions have become less equal. We develop a dynamic general equilibrium trade model that explains these phenomena. The model combines standard search frictions in labor markets with heterogeneous firms that experience ongoing productivity shocks. Each period, firms decide whether to exit or continue producing. Those firms that remain active choose their export volumes and adjust their employment levels through vacancy postings or lay-offs.

Openness matters in our model because it makes profits more sensitive to productivty shocks, as Rodrik (1997) argued. Thus when trade barriers are low, firms drawing negative shocks shed labor relatively rapidly (and perhaps exit), while firms drawing positive shocks acquire new workers relatively rapidly. Further, since openness decreases the rents of the former and increases the rents of the latter, it spreads the wage distribution. After fitting this model to Colombian micro data on establishments and households, we isolate the effects of trade frictions on labor market outcomes using counter-factual simulations. Preliminary results suggest that the mechanisms highlighted by our model can be important.
\end{abstract}




\section{Introduction}

In developing countries, globalization is often blamed for exacerbating wage inequality, reducing job security, and increasing the size of the informal sector. This has been particularly true in Latin America, where many countries that pursued trade liberalization programs also experienced greater wage dispersion, heightened job turnover, and/or informality. ${ }^{1}$ But the extent to which trade liberalization is to blame remains an open question. Labor market outcomes reflect many factors besides foreign competition, and reduced-form regressions have not convincingly isolated causal relationships. To better isolate the effects of openness on developing countries' workers, we formulate a dynamic structural model of trade with labor market frictions. Then we fit our model to plant-level panel data and household survey data from Colombia - a country that in many respects typifies Latin American experiences.

The mechanism that links openness and labor market outcomes in our model is related to one posited by Rodrik (1997). He argued that openness increases the elasticity of demand for goods, and thus makes firms' labor demand functions more sensitive to idiosyncratic productivity shocks. Workers' job security and bargaining power are therefore compromised as trade barriers come down. In our model, although the elasticity of demand for goods is parametrically fixed at home and abroad, openness likewise increases the effects of idiosyncratic productivity shocks on vacancy postings and lay-offs. This occurs mainly because openness shifts the size distribution of producers in favor of large firms, and with production concen-

\footnotetext{
1 "Between the mid-1980s and the beginning of the 1990s, countries in Latin America began trade liberalization programs, with reductions of at least 15 percentage points in the average tariff rate, which fell from an average of 48.9 percent in the prereform years to 10.7 percent in 1999." (Inter-American Development Bank, 2004, p. 137). Haltiwanger et al (2004) document the association between job turnover and openness in Latin America. Goldberg and Pavcnik (2007) survey the evidence linking openness to wage inequality and informality in Latin America and other developing regions.
} 
trated in fewer establishments, idiosyncratic shocks have a bigger influence on job turnover. ${ }^{2}$ The greater volatility in firm-specific labor demand induces associated changes in the equilibrium turnover rate, the wage distribution, and the rate of self-employment/informality.

Our formulation also shares some features with a number of recent trade models that describe the effects of openness on labor markets (Felbermayr et al, 2007; Helpman and Itskhoki, 2007; Helpman, et al, 2008; Egger and Kreickemeier, 2007; Davis and Harrigan, 2008; Amiti and Davis, 2008). ${ }^{3}$ In particular, it embodies Melitz's (2003) basic insight that openness compounds the advantage of relatively efficient firms by creating new exporting opportunities for them, while it compounds the problems of relatively inefficient firms by intensifying the competitive pressures they face. However we depart from this literature in two ways. First, we assume that firms experience ongoing, idiosyncratic productivity shocks (as in Hopenhayn, 1992, and Hopenhayn and Rogerson, 1993), inducing them to adjust their vacancy postings, lay-offs and exit decisions. (as in Bertola and Caballero, 1994, and Bertola and Garibaldi, 2001). ${ }^{4}$ Second, we fit our model to micro data and use it to perform numerical

\footnotetext{
${ }^{2}$ As a simple example of this effect, consider a set of $n$ firms, each of which initially employs $L / n$ workers. If the growth rate in labor demand at the $\mathrm{i}^{\text {th }}$ firm is $g_{i}$, and if $g$ is iid across firms, the variance in end-of-period labor demand is $\operatorname{var}\left[\sum_{i} \frac{L}{n}\left(1+g_{i}\right)\right]=\operatorname{var}(g) \cdot \frac{L^{2}}{n}$. Clearly if the same $L$ workers had been initially divided among fewer firms, the variance in end-of-period employment would have been larger.
}

\footnotetext{
${ }^{3}$ Several less-related linkages between openness and labor market outcomes have been modeled in the recent trade literature. One strand of this literature emphasizes the changes in skill-premia and/or unemployment rates that result from trade-induced changes in the relative demand for different types of labor (e.g., Albrecht and Vroman, 2002; Yeaple, 2005; Davidson et al, 2006). Another characterizes the adjustments in wages, unemployment and labor turnover patterns that derive from trade-induced changes in sectoral output prices (e.g., Kambourov, 2006; Artuc, Chaudhuri and McClaren, 2008). And finally, some studies have focussed on cross-country differences in the flexibility of labor markets as a source of comparative advantage (Davidson et al, 1999; Cunat and Melitz, 2007; Helpman and Itskhoki, 2008).
}

\footnotetext{
${ }^{4}$ Other recent papers that study firm dynamics and labor market frictions in a closed economy context include Cooper et al (2007), Hobijn and Sahin (2007), Koeniger and Prat (2007), and Lentz and Mortensen (2008). Utar (2008) studies firm dynamics and labor market fricttions in an import-competing industry that takes the wage rate as given.
} 
experiments that quantify the effects of openness under alternative assumptions. Simulations at plausible parameter values show that these effects can be important.

While we do not pretend to capture all of the channels through which openness can affect labor market outcomes, our focus on firm-level entry, exit and idiosyncratic productivity shocks is supported by existing empirical evidence on the sources of job turnover and wage heterogeneity. Studies of job creation and job destruction invariably find that most reallocation is due to idiosyncratic (rather than industry-wide) adjustments (Davis et al, 1998; Roberts, 1996; Inter-American Development Bank, 2004). "This is true even in Latin America's highly volatile macro environment," where producer entry and exit alone account for 30-40 percent of job creation and destruction (Inter-American Development Bank 2004, chapter 2). Further, as Goldberg and Pavcnik (2007) note, if openness has had a significant effect on job flows, it has mainly been through intra-sectoral effects: "Most studies of trade liberalization in developing countries find little evidence in support of [trade-induced labor] reallocation across sectors." Finally, while cross-worker differences in wages are obviously partly due to differences in worker characteristics, much is attributable to labor market frictions and firm heterogeneity. ${ }^{5}$

\section{Environment: The Closed Economy}

For expositional clarity, we first develop our model for the case of a closed economy. This formulation extends Bertola and Cabellero (1994) and Bertola and Garibaldi (2001) to a general equilibrium setting with fully articulated product markets, arbitrary (stationary) Markov

\footnotetext{
${ }^{5}$ Studying data from France and the United States, Abowd, et al (1999) and Abowd, et al (2002) show that roughly half of the cross-worker variation in compensation in French workers is due to employer effects. The only study of employer-employee data in developing countries we are aware of is Menezes-Filho and Muendler (2007). This paper does not report results on sources of wage variation.
} 
processes for productivity shocks and endogenous firm entry and exit. Once we have characterized the interactions between the labor markets, product markets, and productivity shocks in this setting, it is straightforward to generalize the analysis to an open economy and allow for intra-sectoral trade.

There are two types of output in our economy — services and industrial goods. The former are non-traded while the latter are tradable, subject to transport costs. Services are supplied by firms and, less efficiently, by unemployed workers engaged in home production. Regardless of their source, services are produced with labor alone, homogeneous across suppliers, and sold in competitive product markets. Firms who supply services use a common constant returns technology, and face no hiring or firing costs.

Industrial goods cannot be home-produced. They must be supplied by firms, which pay a sunk start-up cost to initiate production of a single variety of output. Each firm produces its output using labor alone, and competes in a monopolistically competitive product market. Unlike service sector firms, suppliers of industrial goods are subject to ongoing idiosyncratic productivity shocks, and they must create costly vacancies in order to attract new workers. The shocks they face can equally well be thought of as affecting the relative appeal of their products.

Producer dynamics in the industrial sector resemble those in Hopenhayn and Rogerson (1993) in that firms react to their productivity shocks by optimally hiring, firing or exiting. Also, new firms enter whenever their expected future profit stream exceeds the entry costs they face. However, unlike Hopenhayn and Rogerson, we assume hiring in the industrial sector is subject to search frictions captured by a standard matching function. Further, workers make 
forward-looking decisions concerning which sector to work in and what job offers to accept.

Each worker decides whether to participate in the industrial labor market at the beginning of each period. Those who are already employed in the industrial sector can continue with their current job unless their employer lays them off or shuts down entirely. (They can also quit in order to move to the service sector or to search for other industrial sector jobs, although in equilibrium none find it optimal to do so.) Those not yet employed in the industrial sector can forego certain employment with a service sector firm in order to search for a higherwage industrial sector job, but they risk remaining unemployed if they fail to match with an industrial sector producer. ${ }^{6}$ Those who end up unemployed subsist during the current period by using a relatively inefficient technology to home-produce services.

\subsection{Production Technologies}

All service-sector firms exploit a common constant-returns technology to produce the homogenous good. So with an appropriate choice of output units, we may write their combined supply of services as

$$
S=L_{S},
$$

where $L_{S}$ is labor hired in services.

In the industrial sector, output of producers with productivity level $z$ is given by

$$
q(z, l)=z l^{\alpha},
$$

where $l$ is the labor input and $\alpha>0$. Productivity is firm-specific, independent across firms, and serially correlated. Its evolution is characterized by the transition density $h\left(z^{\prime} \mid z\right)$, which

\footnotetext{
${ }^{6}$ The notion that workers trade job security in a low wage sector for the opportunity to search in a higher wage sector traces back at least to the Harris and Todaro (1970) model.
} 
is common to all firms.

\subsection{Preferences}

Worker-consumers in the economy are homogenous and their measure is normalized to unity.

Each has lifetime utility given by

$$
\mathcal{U}=\sum_{t=1}^{\infty}\left(\frac{1}{1+r}\right)^{t} U\left(s_{t}^{c}, q_{t}^{c}\right),
$$

where $r$ is the rate of time preference, $s_{t}^{c}$ is consumption of services, and $q_{t}^{c}$ is an index of differentiated good consumption. The momentary utility function $U$ takes the form

$$
U\left(s^{c}, q^{c}\right)=\frac{\left(s^{c}\right)^{1-\gamma}\left(q^{c}\right)^{\gamma}}{(1-\gamma)^{1-\gamma} \gamma^{\gamma}}
$$

where $\gamma \in(0,1)$ and our index of industrial goods consumption is

$$
q^{c}=\left(\int_{0}^{N} q^{c}(n)^{\frac{\sigma-1}{\sigma}} d n\right)^{\frac{\sigma}{\sigma-1}} .
$$

Here $N$ is our measure of differentiated varieties, $q_{t}^{c}(n)$ is consumption of variety $n$, and $\sigma>1$ is the elasticity of substitution between varieties.

The price of services is our numeraire, and given our representation of preferences above, the exact price index for the composite good $q^{c}$ is

$$
P=\left(\int_{0}^{N} p(n)^{1-\sigma} d n\right)^{\frac{1}{1-\sigma}}
$$

where $p(n)$ is the price of variety $n$.

Letting $I_{i}$ be the income of worker $i$ and disallowing savings, the period-by-period budget constraint is 


$$
I_{i}=s_{i}^{c}+P q_{i}^{c}
$$

Utility maximization implies that consumer $i$ spends a fraction $\gamma$ of her income on the composite industrial good and her demand for variety $n$ is

$$
q_{i}^{c}(n)=\frac{\gamma I_{i}}{P}\left(\frac{p(n)}{P}\right)^{-\sigma}=D_{i} p(n)^{-\sigma}
$$

where $D_{i}=\gamma I_{i} P^{\sigma-1}$. Finally, since worker-consumers are risk neutral, consumer $i$ enjoys momentary indirect utility

$$
\mathcal{W}_{i}=I_{i} P^{-\gamma}
$$

\subsection{Labor Markets and the Matching Technology}

The service sector labor market is frictionless so, given that the price of services is unity, the service sector wage is $w_{s}=1$. Search frictions make things more complicated in the industrial sector. Each period the number of new matches between unemployed workers and vacancy posting firms is given by

$$
M\left(V, L_{u}\right)=\frac{V L_{u}}{\left(V^{m}+L_{u}^{m}\right)^{1 / m}},
$$

where $L_{u}$ is the measure of unemployed workers searching in industrial sector and $V$ is the measure of vacancies in industry. ${ }^{7}$ Consequently, industrial firms fill each vacancy they post with probability

$$
\phi^{f}\left(V, L_{u}\right)=\frac{M\left(V, L_{u}\right)}{V}=\frac{L_{u}}{\left(V^{m}+L_{u}^{m}\right)^{1 / m}},
$$

\footnotetext{
${ }^{7}$ The functional form of the matching function follows den Haan et al. (2000). It is constant returns to scale, and increasing in both arguments. The advantage relative to the standard Cobb-Douglas form is that it has no scale parameter and the matching rates in implies are bounded between zero and one.
} 
while unemployed workers searching for industrial jobs find matches with probability

$$
\phi^{w}\left(V, L_{u}\right)=\frac{M\left(V, L_{u}\right)}{L_{u}}=\frac{V}{\left(V^{m}+L_{u}^{m}\right)^{1 / m}} .
$$

At the beginning of each period, all workers choose whether to work in industry or services. Workers who choose services are employed with certainty at the wage $w_{s}$, but workers who choose industry may or may not find employment. Those who already hold industrial sector jobs can continue with them so long as they do not lose their jobs because their employers contract or shut down. Those who are not already employed in the industrial sector can begin working there if they successfully match with a vacancy-posting producer. The probabilities of these different events shape workers' sectorial choices, as well as firms' employment policies. We start by describing the latter.

\subsection{Incumbent Firm's Problem}

The demand function (2) and the production function (1) imply that any producer with productivity $z$ who chooses employment level $l$ will earn revenue

$$
r(z, l)=D^{\frac{1}{\sigma}}\left(z l^{\alpha}\right)^{\left(\frac{\sigma-1}{\sigma}\right)},
$$

where $D=\int_{0}^{1} D_{i} d i$ is aggregate demand for differentiated goods.

When choosing employment levels, firms weigh this payoff against wage costs, the effects of changes in $l$ on the their continuation value, and hiring costs. To characterize the latter, let the cost of posting $v$ vacancies for a firm of size $l$ be

$$
C_{h}(l, v)=\frac{c_{h}}{\lambda}\left(\frac{v}{l}\right)^{\lambda}
$$




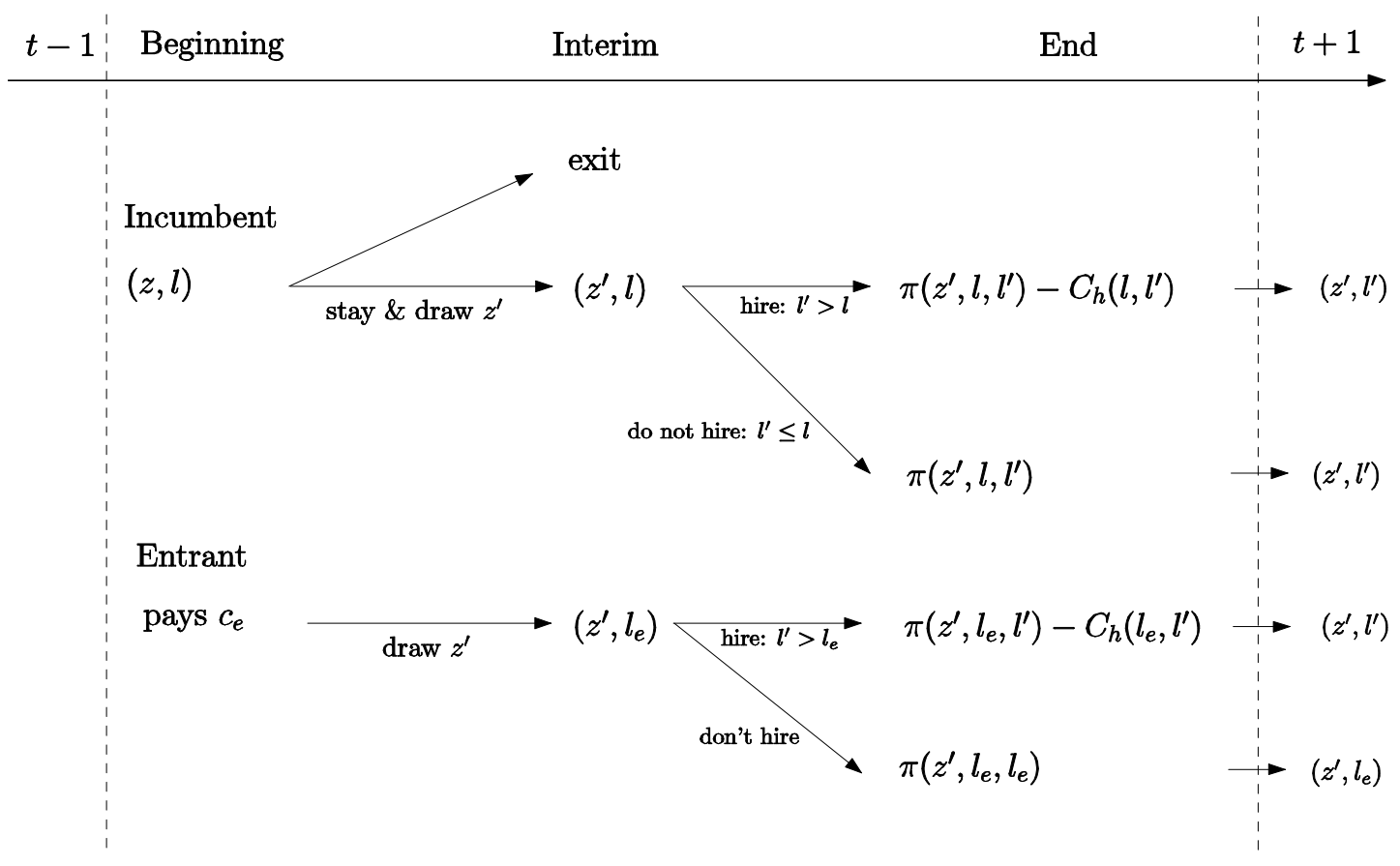

Figure 1: Within-period Sequencing of Events for Firms

where $c_{h}$ and $\lambda>1$ are positive parameters. ${ }^{8}$ Also assume that firms are large in the sense that cross-firm variation in realized arrival rates is ignorable. (That is, all firms fill the same fraction $\phi^{f}$ of their posted vacancies.) It follows that expansion from $l$ to $l^{\prime}$ simply requires the posting of $v=\frac{l^{\prime}-l}{\phi^{f}}$ vacancies and we can define the cost of expanding from $l$ to $l^{\prime}$ workers as

$$
C_{h}\left(l, l^{\prime}\right)=\frac{c_{h}}{\lambda} \frac{1}{\left(\phi^{f}\right)^{\lambda}}\left(\frac{l^{\prime}-l}{l}\right)^{\lambda}
$$

Finally, each firm bargains with its workers individually and continuously, ensuring, as in Stole and Zwiebel (1996) and Cahuc and Wasner (2000), that all workers at a given firm are paid the same wage at a given point in time.

To derive firms' optimal employment policies, we first specify the sequencing events within

\footnotetext{
${ }^{8}$ As discussed in Bertola and Caballero (1994) "convexity is necessary to obtain a well-defined vacancyposting equilibrium when productivity is heterogeneous across firms, as firms with high productivity and low employment levels would want to post infinitely many vacancies for arbitrarily short intervals of time if such policies were not made prohibitively costly."
} 
each period (see Figure 1). An incumbent firm enters the current period with the productivity $z$ and work force $l$, which were determined at the end of the previous period. Immediately the firm decides whether to stay in business or to exit. If it stays, it proceeds to an interim stage in which it observes its current-period productivity realization $z^{\prime}$. Then, taking stock of its updated state, $\left(z^{\prime}, l\right)$, the relevant wage schedules, and the economy-wide worker arrival rate, $\phi^{f}$, it chooses its current period work force, $l^{\prime}$. The firm can decide to hire $\left(l^{\prime}>l\right)$ or fire $\left(l^{\prime} \leq l\right)$ workers. If it hires workers, they are immediately available to produce output in the current period. Finally, revenues accrue and wages and other costs are paid at the end of the period.

Given the presence of search frictions, workers at hiring firms generate rents, and as we will detail shortly, these are bargained over to determine wages. However, since firms can shed workers costlessly, the marginal worker at a firing firm creates no rents and has no bargaining power. Hence expanding and contracting firms face different wage schedules, and current operating profits depend upon both $l$ and $l^{\prime}$. More precisely, defining $w_{h}\left(z^{\prime}, l^{\prime}\right)$ to be the wage function faced by a hiring firm and $w_{f}\left(z^{\prime}, l^{\prime}\right)$ to be the wage function faced by a firing firm, profits are

$$
\pi\left(z^{\prime}, l, l^{\prime}\right)=\left\{\begin{array}{rr}
r\left(z^{\prime}, l^{\prime}\right)-w_{h}\left(z^{\prime}, l^{\prime}\right) l^{\prime}-c_{f} & \text { if } l^{\prime}>l \\
r\left(z^{\prime}, l^{\prime}\right)-w_{f}\left(z^{\prime}, l^{\prime}\right) l^{\prime}-c_{f} & \text { otherwise }
\end{array}\right.
$$

where $c_{f}$, the per-period fixed cost of operation, is common to all firms.

Using (5), the value of a firm in the interim state $\left(z^{\prime}, l\right)$ is given by

$$
\mathcal{V}\left(z^{\prime}, l\right)=\max _{l^{\prime}} \frac{1}{1+r}\left\{\pi\left(z^{\prime}, l, l^{\prime}\right)-C\left(l, l^{\prime}\right)+\max \left(E_{z^{\prime \prime}}\left[\mathcal{V}\left(z^{\prime \prime}, l^{\prime}\right) \mid z^{\prime}\right], 0\right)\right\}
$$

where

$$
C\left(l, l^{\prime}\right)=\left\{\begin{array}{l}
C_{h}\left(l, l^{\prime}\right), \text { if } l^{\prime}>l, \\
0, \text { otherwise }
\end{array}\right.
$$


In turn, the solution to (6) implies an employment policy function, hereafter denoted $l^{\prime}=$ $L\left(z^{\prime}, l\right)$. It also implies an indicator function that distinguishes hiring firms from others,

$$
\mathcal{I}^{h}\left(z^{\prime}, l\right)=\left\{\begin{array}{l}
1, \text { if } L\left(z^{\prime}, l\right)>l, \\
0, \text { otherwise. }
\end{array},\right.
$$

and an indicator function that summarizes firm's beginning-of-period continuation/exit policy

$$
\mathcal{I}^{c}(z, l)=\left\{\begin{array}{l}
1, \text { if } E_{z^{\prime}}\left[\mathcal{V}\left(z^{\prime}, l\right) \mid z\right]>0 \\
0, \text { otherwise. }
\end{array} .\right.
$$

\section{$2.5 \quad$ Entry}

In the steady state, a constant (endogenous) fraction $\mu_{\text {exit }}$ of firms exits the industry. There is an infinite pool of potential entrants, and actual entrants replace this mass of exiting firms by paying a sunk entry cost of $c_{e}$ in terms of the service sector good. Entrants draw their initial productivity from the density function denoted by $f_{e}(z)$ with support $[\underline{z}, \bar{z}]$, and immediately hire $l_{e}>0$ workers at no additional cost. After observing $z$, entrants behave exactly like the incumbent firms in the interim stage, with their interim state given by $\left(z, l_{e}\right)$ - see Figure 1. Free entry implies that

$$
\mathcal{V}_{e}=\int_{\underline{z}}^{\bar{z}} \mathcal{V}\left(z, l_{e}\right) f_{e}(z) d z \leq c_{e},
$$

which holds with equality if there is a positive mass of entrants $M$.

\subsection{Worker's Problem}

Figure 2 presents the intra-period timing of events for workers. Consider first a worker who at the beginning of the current period is employed by an industrial firm in state $(z, l)$. This 
worker learns immediately whether her firm will exit. If her firms exists, she joins the pool of industrial job seekers (enters state $u$ ) in the interim stage. Otherwise, she enters the interim stage as an employee of the same firm that she worked for in the previous period. (No one voluntarily quits because, in equilibrium, firms always pay their workers at least their reservation wage.) Her firm then realizes its new productivity level $z^{\prime}$ and enters the interim state $\left(z^{\prime}, l\right)$. At this point her firm decides whether to hire or fire workers. In the former case it expands its workforce to $l^{\prime}>l$, and she earns $w_{h}\left(z^{\prime}, l^{\prime}\right)$. She is then positioned to start the next period in state $\left(z^{\prime}, l^{\prime}\right)$. In the latter case, she loses her job and reverts to state $u$ with probability $p_{f}=\left(l-l^{\prime}\right) / l$. Finally, with probability $1-p_{f}$ she retains her job, earns $w_{f}\left(z^{\prime}, l^{\prime}\right)$ during the current period, and starts next period in state $\left(z^{\prime}, l^{\prime}\right)$.

Workers in state $u$ search for an industrial job. They are hired by entering and expanding firms that post vacancies. If they are matched with a firm, they receive the same wage as those who were already employed by the firm. If they are not matched, they remain unemployed in the current period, and support themselves by home-producing $b \in[0,1)$ units of the service good. At the start of the next period, they can choose to work in the service sector (enter state $s$ ) or look for a job in the industrial sector (remain in state $u$ ). Likewise, workers who start the current period in the service sector choose between continuing to work at the service wage $w_{s}=1$ and entering the pool of industrial job-seekers. As these workers have the option to choose either labor market, they are said to be in state $o$.

We now specify the value functions for the workers in the interim stage. Going to the service sector generates an end-of-period income of 1 and returns a worker to the $o$ state at 


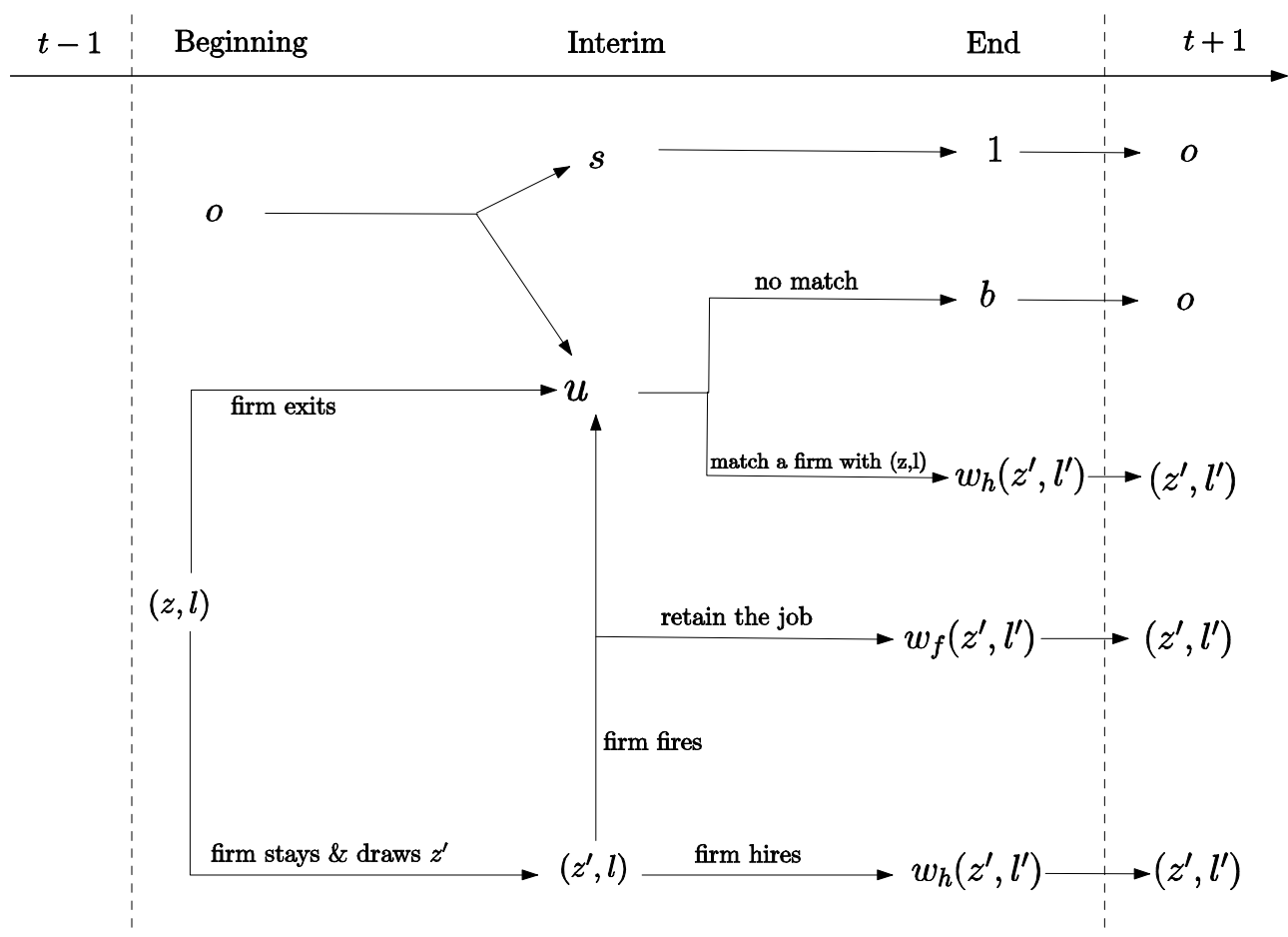

Figure 2: Within-period Sequencing of Events for Workers

the beginning of next period. Accordingly, the interim value of this choice is

$$
J^{s}=\frac{1}{1+r}\left(1+J^{o}\right)
$$

Searching in the industrial sector exposes workers to the risk of spending the period unemployed, supporting themselves by home-producing $b$ units of the service good. But it also opens the possibility of landing on a high-value job. Given the probability of finding a match is $\phi^{w}$, the interim value of searching for an industrial job is given by

$$
J^{u}=\frac{1}{1+r}\left[\left(1-\phi^{w}\right)\left(b+J^{o}\right)+\phi^{w} E J_{h}^{e}\right]
$$

where $E J_{h}^{e}$ is the expected value of being employed in a hiring firm. Given these two values, the value of the sectorial choice is $J^{o}=\max \left\{J^{s}, J^{u}\right\}$. Since both sectors must exist in equilibrium (given consumer preferences), 


$$
J^{o}=J^{s}=J^{u}
$$

The expected value of matching with an industrial job, $E J_{h}^{e}$, depends on the distribution of hiring firms and the value of the jobs they offer. For workers who match with a hiring firm in the interim state $\left(z^{\prime}, l\right)$, the interim period value is given by

$$
J_{h}^{e}\left(z^{\prime}, l\right)=\frac{1}{1+r}\left[w_{h}\left(z^{\prime}, l^{\prime}\right)+J^{e}\left(z^{\prime}, l^{\prime}\right)\right]
$$

where $l^{\prime}=L\left(z^{\prime}, l\right)$ and $J^{e}\left(z^{\prime}, l^{\prime}\right)$ is the value of being employed at an industrial firm in state $\left(z^{\prime}, l^{\prime}\right)$ at the start of the next period.

The expected value of being employed in a hiring firm depends on the density of vacancies across firm. This density is given by

$$
g\left(z^{\prime}, l\right)=\frac{v\left(z^{\prime}, l\right) \tilde{f}\left(z^{\prime}, l\right) \mathcal{I}^{h}\left(z^{\prime}, l\right)}{\int_{z^{\prime}} \int_{l} \widetilde{f}\left(z^{\prime}, l\right) \mathcal{I}^{h}\left(z^{\prime}, l\right) v\left(z^{\prime}, l\right) d l d z^{\prime}},
$$

where $v\left(z^{\prime}, l\right)=[L(z, l)-l] / \phi^{f}$ is the vacancy policy function for the firm and $\widetilde{f}(z, l)$ is the unconditional density of firms over $(z, l)$ in the interim stage. Accordingly, the expected value of a match for a worker, as perceived at the interim stage $\left(z^{\prime} . l\right)$, is

$$
E J_{h}^{e}=\int_{z^{\prime}} \int_{l} J_{h}^{e}\left(z^{\prime}, l\right) g\left(z^{\prime}, l\right) d l d z^{\prime}
$$

It remains to specify the unconditional value of starting the period matched with an industrial firm, $J^{e}(z, l)$, which appears in (12). An industrial firm that starts a period in state $(z, l)$ can exit right away. Otherwise, it can be a hiring or a firing firm depending on the 
realization of the new productivity shock. Then, $J^{e}(z, l)$ is given by

$$
J^{e}(z, l)=I^{c}(z, l) \int_{z^{\prime}} \widetilde{J}^{e}\left(z^{\prime}, l\right) h\left(z^{\prime} \mid z\right) d z^{\prime}+\left(1-I^{c}\left(z^{\prime}, l\right)\right) J^{u}
$$

where, since firing firms pay workers their reservation wage, the continuation value is

$$
\widetilde{J}^{e}\left(z^{\prime}, l\right)=\left\{\begin{array}{l}
\frac{1}{1+r}\left[w_{h}\left(z^{\prime}, l^{\prime}\right)+J^{e}\left(z^{\prime}, l^{\prime}\right)\right], \text { if } l^{\prime} \geq l \\
J^{u} \quad \text { otherwise. }
\end{array}\right.
$$

where $l^{\prime}=L\left(z^{\prime}, l\right)$. A worker who starts the period in state $(z, l)$ and keeps her job, i.e. if $I^{c}(z, l)=1$, will end up in a hiring or firing firm. If she is with a hiring firm then she will earn the hiring wages this period and start the the next period in exactly the same situation. If she is with a firing firm, then her continuation value is simply given by $J^{u}$.

Given the wage schedules, firms employment policies, and the distribution of firms, the system of equations described in this section determines workers' payoffs and their associated behavior.

\subsection{Wage Schedules}

All firms that decide to hire post vacancies. After the matching takes place, the firm bargains with its workers simultaneously and on a one-to-one basis, treating each worker as the marginal one. Hiring firms cannot begin bargaining with their workers until they have finished posting their current-period vacancies and matching has taken place. As a result, vacancy posting costs are already sunk and workers who walk away from the bargaining table cannot be replaced in the current period. Similarly, if an agreement between firm and the worker is not reached, the worker remains unemployed in the current period. These timing assumptions create rents to be split between the firm and the worker. 
As detailed in Appendix 1, it follows that the wage schedule for expanding/replenishing firms with an end-of-period state $\left(z^{\prime}, l^{\prime}\right)$ is given by

$$
w_{h}\left(z^{\prime}, l^{\prime}\right)=(1-\beta) J_{\text {end }}^{u}\left(z^{\prime}, l^{\prime}\right)+\Gamma(\alpha, \beta, \sigma) D^{\frac{1}{\sigma}}\left(z^{\prime}\right)^{\frac{\sigma-1}{\sigma}}\left(l^{\prime}\right)^{-\left[\frac{\alpha}{\sigma}+(1-\alpha)\right]}
$$

where $\Gamma(\alpha, \beta, \sigma)=\frac{\alpha \beta(\sigma-1)}{\sigma(1-\beta)+\alpha \beta(\sigma-1)}$, and $J_{\text {end }}^{u}\left(z^{\prime}, l^{\prime}\right)$ is the value of unemployment for a worker who is bargaining with a firm at the end of the period - Figure 2. Note that if $\beta=0$, i.e. all the bargaining power is with the firm, the firm pays reservation wages equal to the flow value of the outside option, $J^{u}$.

The marginal worker at a contracting firm generates no rents, so the firing wage just matches their reservation wage. It is given by (see Appendix 1)

$$
w_{f}\left(z^{\prime}, l^{\prime}\right)=(1+r) J^{u}-J^{e}\left(z^{\prime}, l^{\prime}\right),
$$

Note that, unlike $b+J^{o}, w_{f}\left(z^{\prime}, l^{\prime}\right)$ varies across firms, reflecting their different future prospects. It can be less than the value of home production, as firing firms may draw a better $z$ value in the future and raise their wages.

\section{Closed Economy Equilibrium}

Five basic conditions characterize our equilibrium. First, the distribution of firms over $(z, l)$ states reproduces itself each period through the Markov processes on $z$, the policy functions (including hiring, firing, entry and exit), and the productivity draws firms receive upon entry. Second, supply matches demand for services and for each differentiated good, where supplies are determined by employment and productivity levels in each type of good. Third, the flow of workers into unemployment matches the flow of workers out of unemployment - that is, the Beveridge condition holds. Fourth, aggregate income matches aggregate expenditure. 
And finally, workers optimally choose the sector in which they are working or seeking work. Appendix 2 provides the algebraic details of these conditions, and Appendix 5 summarizes the numerical solution algorithm we use to find the associated equilibrium.

\section{Open Economy Equilibrium}

\subsection{Symmetric Countries}

Now consider an open economy version of our model in which two symmetric countries trade industrial goods with one another, subject to iceberg transportation costs and fixed exporting costs. Transport costs are parameterized by $\tau$, which denotes the amount of each good that must be shipped in order for one unit to arrive at its foreign destination. Fixed costs are denoted by $c_{x}$, and must be paid once per period by each exporting firm, regardless of its total shipments. These fixed costs keep firms with high labor costs and/or low productivity levels out of foreign markets.

Demand for an exporting firm comes from domestic and foreign consumers. By symmetry, product-specific demand functions have the same intercept $D$ in both markets. However trade costs induce cross-country asymmetries in sales. If a firm in state $(z, l)$ exports some fraction $\eta$ of its output, its export revenues are:

$$
r_{x}(z, l, \eta)=D^{\frac{1}{\sigma}}\left[\frac{\eta}{\tau} z l^{\alpha}\right]^{a}
$$

and its domestic revenues are

$$
r_{d}(z, l, \eta)=D^{\frac{1}{\sigma}}\left[(1-\eta) z l^{\alpha}\right]^{a}
$$

where $a=\frac{\sigma-1}{\sigma}$. Accordingly, if the firm chooses $\eta$ optimally, its total revenue (net of fixed 
exporting costs) is:

$$
\begin{aligned}
r(z, l) & =\max _{\eta \in[0,1]}\left(r_{d}(z, l, \eta)+r_{x}(z, l, \eta)-c_{x} \mathcal{I}^{x}(z, l)\right) \\
& =\max \left\{\begin{array}{c}
D^{\frac{1}{\sigma}}\left(z l^{\alpha}\right)^{a}\left[\left(\eta^{*} / \tau\right)^{a}+\left(1-\eta^{*}\right)^{a}\right]-c_{x} \mathcal{I}^{x}(z, l) ; \\
D^{\frac{1}{\sigma}}\left(z l^{\alpha}\right)^{a}
\end{array}\right.
\end{aligned}
$$

where $\eta^{*}=\frac{1}{1+\tau^{\sigma-1}}$ and $\mathcal{I}^{x}(z, l)=1_{\eta>0}$ is an indicator function that equals one if the firm exports a non-zero quantity of its output. Clearly, since $\eta^{*}>0$, firms can always increase their gross revenues by exporting and there is a threshold value of $z l^{\alpha}$ above which firms do best to export. Once the closed economy revenue function (4) has been replaced with (17), and we have redefined our price and quantity indices in the usual way for intra-industry trade (see Appendix 3), the analysis proceeds exactly as before.

Embedded in our general equilibrium model, this standard revenue function delivers a number of desirable features. First, for any given $(z, l)$, it implies that the marginal revenue product of labor is larger when the economy is open. This is the underlying reason that productivity shocks induce larger adjustments in vacancy postings or firings when foreign markets are accessible. Second, since larger revenues at a given $(z, l)$ mean more surplus to bargain over, it is also the reason that the wage paid by a firm that exports in state $(z, l)$ is higher than what it is in the closed economy equilibrium. This result is consistent with the empirical finding that, controlling for employment, exporters pay higher wages (Bernard and Jensen, 1999). Third, combined with the fact that search frictions make marginal costs vary across firms with identical $z$ values, it explains why productive efficiency is a noisy predictor for exporting status. ${ }^{9}$ Fourth, re-interpreting $z$ shocks to be product appeal indices rather

\footnotetext{
${ }^{9}$ This fact has attracted some attention recently. Hallak and Sividasan (2008) explain it by assuming that (1) firms differ in terms of both their quality and their productivity efficiency, and (2) exporting requires that firms meet a minimum quality standard.
} 
than productivity indices, it explains why exporters manage to be larger than non-exporters, even though they charge higher prices and pay higher wages. ${ }^{10}$

Finally, and perhaps most interestingly, this expression implies that firms' exporting status affects their total revenue for a given amount of labor and a given productivity level. (Consider, for example, the change in revenue induced by a reduction in $\tau$ sufficiently large to cause a firm to begin exporting.) Thus, it provides a new interpretation for the common finding that measured productivity - i.e., deflated revenue per unit input bundle - is higher among exporters. ${ }^{11}$ The reason this result emerges is that labor market frictions prevent firms from freely adjusting their size as exporting opportunities come and go.

\subsection{The Small Country Case}

The model can be modified to represent a small open economy such that domestic conditions do not affect the foreign price index, the extensive margin of imports, or foreign income levels.

We normalize the price of the composite import good to 1 . Since we have a domestic and a foreign numeraire now, there is an exchange rate $\varepsilon_{x}$ which determines their parity. Iceberg trade costs are still denoted by $\tau$ for exports, and there is an ad-valorem import tariff $\tau_{m}$. The domestic price of imports is thus $\left(1+\tau_{m}\right) \varepsilon_{x}$.

Let $D_{F}^{\$}$ and $D_{F}=\varepsilon_{x} D_{F}^{\$}$ be foreign income in foreign and domestic currencies, respectively.

Then export revenues for a firm in state $(z, l)$ are given by

$$
r_{x}(z, l, \eta)=D_{F}^{\frac{1}{\sigma}}\left[\frac{\eta}{\tau} z l^{\alpha}\right]^{a}
$$

As above, firms solve a static problem to determine what fraction of output they should

\footnotetext{
${ }^{10}$ Kugler and Verhoogen (2008) note that this pattern could alternatively be due to complementarities in production between worker ability and product quality.

${ }^{11}$ In support of this interpretation, De Loecker and Warzynski (2009) report evidence that mark-ups are higher among exporting firms.
} 
export. Hence their revenue function is

$$
\begin{aligned}
r(z, l) & =\max _{\eta \in[0,1]}\left(r_{d}(z, l, \eta)+r_{x}(z, l, \eta)-c_{x} \mathcal{I}^{x}(z, l)\right) \\
& =\max \left\{\begin{array}{c}
{\left[D_{H}^{\frac{1}{\sigma}}\left(1-\eta^{*}\right)^{a}+D_{F}^{\frac{1}{\sigma}}\left(\frac{\eta^{*}}{\tau}\right)^{a}\right]\left(z l^{\alpha}\right)^{a}-c_{x} \mathcal{I}^{x}(z, l),} \\
D_{H}^{\frac{1}{\sigma}}\left(z l^{\alpha}\right)^{a}
\end{array}\right.
\end{aligned}
$$

where $\eta^{*}=1 /\left(1+\frac{D_{H}}{D_{F}} \tau^{\sigma-1}\right)$ is the optimal fraction of output to export, given foreign market participation.

Given our foreign price normalization, the domestic price index is

$$
P=\left[\left(\left(1+\tau_{m}\right) \varepsilon_{x}\right)^{1-\sigma}+\widetilde{p}_{d}^{1-\sigma}\right]^{\frac{1}{1-\sigma}}
$$

where $\widetilde{p}_{d}^{1-\sigma}=N \iint p_{d}(z, l)^{1-\sigma} f(z, l) d z d l$ is the price index of domestic sales of domestic varieties with $f(z, l)$ denoting the unconditional distribution of firms over state $(z, l)$ at the end of the period. In turn, import demand is

$$
q_{m}=\left[\frac{\gamma I}{P}\right]\left(\frac{\left(1+\tau_{m}\right) \varepsilon_{x}}{P}\right)^{-\sigma}=D_{H}\left[\left(1+\tau_{m}\right) \varepsilon_{x}\right]^{-\sigma},
$$

where $D_{H}=\gamma I P^{\sigma-1}$ is the domestic demand intercept, as before. Domestic expenditure on imports is $E_{m}=q_{m}\left(1+\tau_{m}\right) \varepsilon_{x}$. Because of the tariff wedge, this figure is higher than what is actual paid to foreigners (in domestic currency). Denoting the latter by $R_{m}$,

$$
R_{m}=\frac{E_{m}}{1+\tau_{m}}=\frac{D_{H}\left[\left(1+\tau_{m}\right) \varepsilon_{x}\right]^{1-\sigma}}{1+\tau_{m}}=D_{H}\left(1+\tau_{m}\right)^{-\sigma} \varepsilon_{x}^{1-\sigma} .
$$

Total tariff revenues, $T_{m}=R_{m} \tau_{m}$, are rebated back to consumers.

Total export revenue of the country is given by

$$
R_{x}=N \int_{z} \int_{l_{e}}^{\infty} r_{x}(z, l) \mathcal{I}^{x}(z, l) f(z, l) d l d z
$$

Trade balance holds when $R_{m}=R_{x}$. In Appendix 3, we show that if all other market clear, trade balance holds by Walras' Law. 


\section{Quantitative Analysis}

\subsection{An Application to Colombia}

To explore the implications of the small-country version of our model, we use a combination of econometric estimation and calibration techniques to fit it to Colombia. This country suits our purposes for several reasons. First, Colombia underwent a significant trade liberalization during the late 1980s and early 1990s, reducing its average nominal tariff rate from 21.5 percent to 11 percent (Table 1). Second, despite stable average unemployment rates, these trade reforms were associated with an increase in job turnover rates from 18.4 percent to 23 percent, an increase in informal self-employment from 17.8 to 20.7 , and an increase of 0.34 in the ratio of wages at the $90^{t h}$ percentile to wages at the $10^{\text {th }}$ percentile, controlling for observable worker characteristics (Table 1). These patterns are typical of Latin American experiences. Finally, although Colombia did experience some macro shocks during the period

of interest, they were relatively mild. Thus the consequences of Colombia's liberalization are relatively likely to come through in its data. 
Table 1: Trade Reforms and Labor Market Outcomes - Colombia ${ }^{12}$

\begin{tabular}{lll}
\hline \hline Variable & pre-liberalization & post-liberalization \\
\hline Average nominal import tariff & 21.50 & 11.30 \\
Job turnover rate & 18.43 & 22.95 \\
Economy-wide unemployment rate & 9.99 & 9.87 \\
Informal self-employment rate & 17.79 & 20.68 \\
Log wage gap $\left(90^{t h}\right.$ versus $10^{t h}$ percentile) & 1.43 & 1.51 \\
\hline \hline
\end{tabular}

\subsection{The Revenue Function and Productivity Process}

The job turnover and wage inequality documented in Table 1 help us to calibrate our model, as we will discuss shortly. But the parameters that characterize the revenue function and the productivity process can be estimated econometrically using Colombia's annual industrial survey. Note that the revenue function (18) and CES preferences imply that log revenues (gross of fixed exporting costs) can be written as a function of employment, productivity and an index of market-wide demand, $d_{H}=\ln \left[D_{H}^{\frac{1}{\sigma}}\left(1-\eta^{*}\right)^{a}\right]$, an index of the percentage increase in total demand associated with exporting, $d_{F}=\ln \left[D_{F}^{\frac{1}{\sigma}}\left(\eta^{*} / \tau\right)^{a} \cdot e^{-d_{H}}+1\right]$, and an indicator for whether firm $i$ is an exporter, $\mathcal{I}_{i t}^{x}$ :

$$
\ln r_{i t}=d_{H}+\mathcal{I}_{i t}^{x} d_{F}+\frac{\sigma-1}{\sigma} \ln z_{i t}+\alpha \frac{\sigma-1}{\sigma} \ln l_{i t}
$$

\footnotetext{
${ }^{12}$ Pre-liberalization data covers 1986-88 period for tariffs, 1978-91 for job turnover, 1988-91 for the unemployment rate, 1986-90 for wage inequality, and 1986-90 for informal sector self-employment. Post reform data are for 1992-98, 1992-99, 1992-98, 1992-99, 1992-98 periods, respectively. The tariff data come from Attanasio, Goldberg and Pavcnik (2004), Table 1a. Job turnover figures are based on DANE's annual industrial survey, which covers all manufacturing establishments with at least 10 workers. The log wage distribution is based on the residuals from a Mincerian regression of log wages on education, age, and sectoral and occupational dummies. The data set pools biennial household survey data from Colombia's national statistical agency (DANE) for the period 1986-98. Coefficients on all variables are allowed to shift through time in order to exclude changing skill premiums as a source of dispersion. The informal self employment rate is constructed from the same data base. It is the fraction of the work force that is self-employed, non-professional, and informal (i.e., not paying social security).
} 
Further, assuming that $\ln (z)$ follows an exogenous $\operatorname{AR}(1)$ process,

$$
\ln z_{i t}=\rho \ln z_{i t-1}+\epsilon_{i t},
$$

equation (19) can be restated as:

$$
\begin{aligned}
\ln r_{i t}= & \left(d_{H}+\mathcal{I}_{i t}^{x} \cdot d_{F}\right)-\rho\left(d_{H}+\mathcal{I}_{i t-1}^{x} d_{F}\right)+\rho \ln r_{i t-1} \\
& -\alpha \rho\left(\frac{\sigma-1}{\sigma}\right) \ln l_{i t-1}+\alpha\left(\frac{\sigma-1}{\sigma}\right) \ln l_{i t}+\frac{\sigma-1}{\sigma} \epsilon_{i t}
\end{aligned}
$$

If we could obtain consistent estimates of the coefficients that appear on the right-handside observable variables, these would allow us to infer consistent estimates of $\rho, \alpha$, and $\sigma$. Also, the variance of the error term would allow us to infer $\sigma_{\varepsilon}$, the standard deviation of error terms in (20). However, selection bias and simultaneity bias prevent us from consistently estimating (21) with ordinary least squares. The former problem occurs because firms choose whether to exit the market partly on the basis of their $\epsilon_{i t}$ realizations, so the $\epsilon_{i t}$ realizations observed for active producers are not random draws from the unconditional distribution of $\epsilon^{\prime} s$. The latter problem occurs because firms' current exporting decisions and employment levels are chosen after the current realization on $\epsilon$ is observed, so $\epsilon_{i t}$ is correlated with both $\mathcal{I}_{i t}^{x}$ and $\ln l_{i t}$. Appendix 4 develops a generalized method of moments (GMM) estimator related to Olley and Pakes' (1996) that deals with both problems.

Applying this estimator to the set of all Colombian manufacturing plants observed for at least three years during the pre-liberalization period 1982 and 1991, we obtain the results summarized in Table 1 below. ${ }^{13}$ Since $\sigma$ proved to be poorly identified, we fixed this parameter

\footnotetext{
${ }^{13}$ The data are annual observations on all manufacturing firms with at least 10 workers. They were collected by Colombia's National Statistics Department (DANE) and cleaned as described in Roberts (1996). Given that fixed capital and intermediate inputs do not appear in our model, we define revenue to be the value of output net of intermediate input and capital costs. Annual capital costs are 10 percent of the book value of firms' capital stocks.
} 
at several values typical of the literature: $\sigma=5$ and $\sigma=8$. All remaining parameters are estimated with considerable precision and fall in plausible ranges. Note also that the results are not very sensitive to $\sigma$, although the lower $\sigma$ value is associated with somewhat smaller estimates for $\alpha$ and $\rho$, and a modestly larger estimate for $\sigma_{\varepsilon}$. We will use the $\sigma=8$ estimates for our baseline calibration.

Table 2: Revenue function and productivity process

\begin{tabular}{l|lll|lll}
\hline \hline & \multicolumn{3}{|c|}{$\sigma=8$} & \multicolumn{3}{c}{$\sigma=5$} \\
\hline parameter & estimate & std. error & $z$-ratio & estimate & std. error & $z$-ratio \\
\hline$\alpha$ & 0.785 & 0.005 & 165.573 & 0.725 & 0.004 & 169.914 \\
$\rho$ & 0.814 & 0.023 & 35.975 & 0.581 & 0.021 & 27.239 \\
$\sigma_{\varepsilon}$ & 0.546 & 0.008 & 69.373 & 0.582 & 0.008 & 74.283 \\
$d_{H}$ & 0.214 & 0.004 & 51.409 & 0.215 & 0.004 & 51.418 \\
$d_{F}$ & 0.214 & 0.019 & 11.030 & 0.180 & 0.019 & 9.318 \\
\hline
\end{tabular}

\subsection{Remaining Parameters}

The results in Table 2 provides us with consistent estimates of $\alpha, \rho, \sigma_{\varepsilon}$, and $d_{F}$, and determine our choices for $\sigma$. Several of the remaining parameters can be selected based on observable aggregates. First, the real borrowing rate in Colombia fluctuated around 15 percent between late 1980s and early 2000s, so we set $r$ to be 0.15 (Bond et al, 2008). Second, the share of tradables in total consumption expenditure in Colombia was about 40 percent in 2005 (Wold Bank, 2008, Table 11, p. 134). ${ }^{14}$ This allows us to set $\gamma$ to be 0.4 .

We take several other parameters from the existing literature. Following den Haan, Ramey and Ramey (2000), we set the elasticity of the matching function, $m$, to be 1.27. And following Yashiv (2000), we take the curvature of labor adjustment costs, $\lambda$, to be 4 . Finally, as a

\footnotetext{
${ }^{14}$ In order to find the expenditure share on tradables we sum the expenditure shares for food and nonalcoholic beverages, alcoholic beverages and tobacco, clothing and footwear. We also added half of furnishing, household equipment and maintenance and half of other consumption items as tradable. This leaves housing, water, electricity, health, transportation, communication, recreation and culture, education, restaurants and hotels as non-tradable items.
} 
benchmark we give equal bargaining power to firms and workers, i.e. $\beta=0.5$, assume that entrants have start with one worker, i.e. $l_{e}=1 .^{15}$

Table 3: Parameter Values

(parameters that are set before simulations)

\begin{tabular}{llll}
\hline \hline Parameter & Value & Description & Observation \\
\hline$\alpha$ & 0.785 & production function & Estimates from Table 2 \\
$\rho$ & 0.814 & persistence of $z$ process & Estimates from Table 2 \\
$\sigma_{\varepsilon}$ & 0.546 & standard deviation of shocks to $z$ & Estimates from Table 2 \\
$D_{F}$ & 6.87 & foreign demand level & Estimates from Table 2 \\
$\sigma$ & 8 & elasticity of subs. between dif. goods & Various studies \\
\hline$r$ & 0.15 & interest rate & Bond, Utar, Tybout (2008) \\
$\gamma$ & 0.4 & share of $Q$ sector in utility & World Bank (2005) \\
$m$ & 1.27 & elasticity of matching function & den Haan, Ramey and Ramey (2000) \\
$\lambda$ & 4 & curvature of labor adjustment & Yashiv (2000) \\
\hline$\beta$ & 0.5 & bargaining power & - \\
$l_{e}$ & 1 & employment at the entering firm & - \\
\hline \hline
\end{tabular}

Table 3 collects the parameters discussed thus far, and implies that six parameters remain to be determined: the fixed cost of operation $c_{f}$, the vacancy posting cost parameter $c_{h}$, the fixed cost of exporting $c_{x}$, the value of home production $b$, iceberg trade $\operatorname{costs} \tau$, and the value of entry $c_{e}$. The value of entry is determined endogenously in the model to satisfy the free entry condition, as in Hopenhayn and Rogerson (1993). The rest of parameters are calibrated to match an equal number of targets. Specifically, to pin down $c_{f}, c_{h}, c_{x}$, and $b$, we select four natural targets: the firm exit rate, the job turnover rate, the fraction of firms that export, and the unemployment rate. The firm exit rate and the fraction of firms that exit are calculated from Colombian plant level data for the pre-liberalization period, 1978-91. The job turnover rate is calculated from Inter-American Development Bank Job Flows Data Set for 1978-1992 period. The unemployment rate is taken from Inter-American Development Bank (2004), and is based on DANE's biennial household surveys.

\footnotetext{
${ }^{15}$ Although $l_{e}=1$, by the time firms begin production they will have adjusted their initial labor force, and their observed employment will reflect their initial productivity.
} 
Finally, the estimates in Table 1 determine the ratio of domestic demand to world demand for differentiated goods, $D_{H} /\left(D_{H}+D_{F}\right)$. Assuming that all countries spend the same fraction of their income on differentiated goods, this ratio can be calculated as the ratio of Colombia's GDP to the GDP of its trading partners. ${ }^{16}$ Our calculations show that this ratio is about 0.0617 so we choose $\tau$ to generate the same ratio. Table 4 shows the calibrated parameters while Table 5 reports the targeted versus simulated values.

Table 5: Calibration

\begin{tabular}{|c|c|c|c|c|c|}
\hline \multicolumn{3}{|c|}{ Calibrated Parameter Values } & \multicolumn{3}{|c|}{ Calibration Targets } \\
\hline Par. & Value & Description & Target & Data & Model \\
\hline$c_{f}$ & 0.54 & fixed cost of oper. & Exit rate & 0.1098 & 0.1181 \\
\hline$c_{h}$ & 21.54 & vacancy posting cost & Job turnover & 0.1843 & 0.1816 \\
\hline$c_{x}$ & 0.19 & fixed exporting cost & Export rate & 0.1142 & 0.1165 \\
\hline$b$ & 0.1 & value of hhd. prod. & Unempl. & 0.0859 & 0.0936 \\
\hline$\tau$ & 1.813 & iceberg trade costs & Rel. demand & 0.0617 & 0.0617 \\
\hline$c_{e}$ & 2.29 & entry cost & & & \\
\hline
\end{tabular}

\subsection{Simulated effects of openness: small country case}

We are now prepared to examine the effects of trade reforms in our calibrated model. To do so we reduce the iceberg trade costs from 1.813 to 1.65 . This reduction generates an increase in the fraction of firms that export from 12.2 percent to 21.2 percent, which is in line with Colombian liberalization experience.

Table 6 shows how key labor market statistics change with the trade reforms. Note first that trade liberalization increases job turnover by 1.9 percentage points, which is about half of the increase in the data.. Thus, while our model does not explain the entire 4.5 percentage point increase that Colombia experienced, it accounts for a significant fraction of the

\footnotetext{
${ }^{16}$ We take the GDP numbers from Penn World Tables. We calculate GDP of Colombia's trade partners as a trade weighted average of their GDPs. The trade data come from Feenstra et al's (2005) data set at http://cid.econ.ucdavis.edu/data/undata/undata.html
} 
change. That is, increased sensitivity to productivity shocks among exporters appears to be a significant phenomenon.

Table 6: The Effects of Trade Reform -Labor Markets

\begin{tabular}{lllll}
\hline \hline Variable & $\tau=1.813$ & $\tau=1.65$ & Difference (model) & Difference (data) \\
\hline Fraction of Firms that Export & 12.2 & 21.2 & 10 & 10 \\
Job Turnover & 18.16 & 20.07 & 1.91 & 4.52 \\
Unemployment, or & 9.21 & 9.34 & 0.13 & -0.12 \\
Informal self-employment & & & & 2.89 \\
$90-10$ Wage Inequality & 1.97 & 2.11 & 0.14 & 0.08 \\
\hline \hline
\end{tabular}

In a sense, we have stacked the deck against finding large turnover effects. Our model filters all shocks to the prices of imported goods through a general price index, and thus does not allow idiosyncratic shocks to foreign suppliers' prices to affect different Colombian firms differently. If we were to use a nested demand system in which different domestic producers compete with different foreign exporters, the effects of openness on job turnover would be magnified. ${ }^{17}$ And since all producers compete with imports while only 10 to 20 percent export, the effects could be dramatic.

Note next that openness also causes more wage inequality in our model. This is not a skillpremium effect; rather it reflects the fact that exporters who experience positive productivity shocks enjoy relatively large rents when trade costs are low. Thus expanding exporters pay larger wage premiums to their workers than they would have in a more closed economy. The left-hand tail of the wage distribution is also stretched by openness, but for a more subtle reason. Large and productive firms get occasional negative shocks, so they shed labor. However, the option value of remaining in such a firm is higher in an open environment because if the firm experiences a positive shock, it will rehire at higher wages. So workers who stay

\footnotetext{
${ }^{17}$ Atkeson and Burstein (forthcoming) provide an example of this type demand specification.
} 


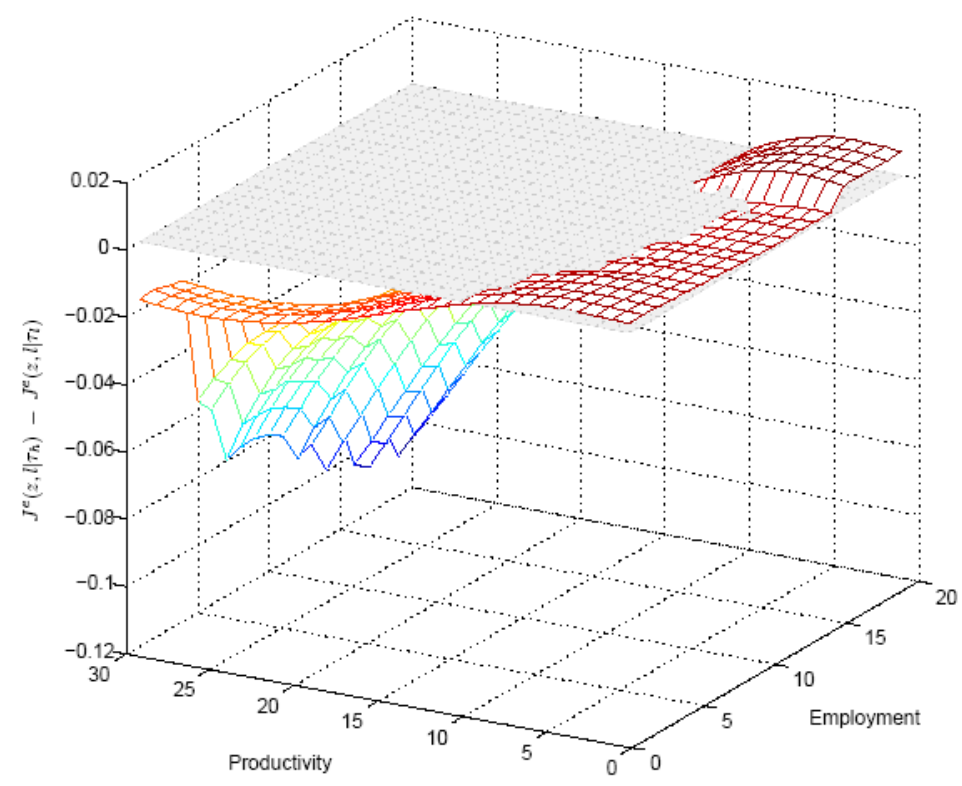

accept lower wages. Unlike with our turnover results, the model over-predicts by a modest amount the extra wage dispersion caused by Colombia's trade liberalization.

Despite the higher job turnover and greater wage inequality that our model predicts, it does not suggest that aggregate unemployment rates should respond much to openness. If one equates self-employment in our model with unemployment in the official statistics, this is consonant with Colombian (and Latin American) experiences. On the other hand, if one equates self-employment with working alone in the informal sector, our model under-predicts responses to globalization in this respect (refer to Table 1).

Finally, it is interesting to examine the welfare effects of opening. Aggregating across consumers, we find that Colombia's tariff reductions increased welfare by 1.5 percent. But different types of workers fared differently. Figure 1 depicts the change in the value of being a worker at firms located throughout $(z, l)$ space, going from $\tau=1.65$ to $\tau=1.813$. Not surprisingly, workers fortunate enough to be employed by high productivity firms do better 
in the relatively open environment. This is particularly true at the largest productive firms, which have the most rents to share with their workers.

\section{Summary}

In Latin America and elsewhere, globalization has been associated with less job security, more wage inequality, and more informality. We have formulated a dynamic structural model that explains these association as a consequence of heightened firm responsiveness to idiosyncratic productivity shocks, and we have shown that this mechanism alone could account for a substantial fraction of the heightened volatility and wage dispersion in Colombia.

In addition to providing a lens through which to interpret recently-observed changes in Latin American labor markets, our paper makes several methodological contributions. First, we have generalized the representation of labor markets developed by Bertola and Caballero (1994) to an open economy setting with fully articulated product markets, multiple sectors, and arbitrary Markov processes for productivity shocks. Second, we have demonstrated how to quantify some welfare and distributional effects of openness postulated by Rodrik (1999). ${ }^{18}$ Finally, we have developed a means to characterize plant-level productivity processes that does not require us to observe a measure of physical output, matches a large set of sytlized facts, and is robust with respect to simultaneity bias and selection bias.

\footnotetext{
${ }^{18}$ Previous attempts to examine Rodrik's conjecture empirically have amounted to tests for structural shifts in the elasticity of demand for labor, pre- versus post-globalization.
} 


\section{Appendix 1: The Wage Functions}

\section{Hiring Wages}

In order to characterize wages in hiring firms, we first determine the total surplus for a firm and a worker that are matched in the end-of-period state $\left(z^{\prime}, l^{\prime}\right)$. At the time of bargaining, the surplus that the marginal worker generates for a firm is given by

$$
\Pi^{f i r m}\left(z^{\prime}, l^{\prime}\right)=\frac{1}{1+r}\left[\frac{\partial \pi\left(z^{\prime}, l^{\prime}\right)}{\partial l^{\prime}}+\mathcal{I}^{c}\left(z^{\prime}, l^{\prime}\right) \int_{z^{\prime \prime}} \mathcal{I}^{h}\left(z^{\prime \prime}, l^{\prime}\right) \frac{\partial \mathcal{V}\left(z^{\prime \prime}, l^{\prime}\right)}{\partial l^{\prime}} h\left(z^{\prime \prime} \mid z^{\prime}\right) d z^{\prime \prime}\right]
$$

Note that at the time of bargaining, the vacancy posting and matching process are over. As a result, if the bargaining fails, the firm is simply left with less workers. The surplus that a marginal worker generates consists of two parts: the current increase in the firms' profits, i.e. marginal revenue product net of wages, and the marginal value of being in state $\left(z^{\prime}, l^{\prime}\right)$ at the start of the next period. If the firm does not exit next period, i.e. if $\mathcal{I}^{c}\left(z^{\prime}, l^{\prime}\right)=1$, the marginal worker will have a positive value for the firm only if the firm decides to hire, i.e. $\mathcal{I}^{h}\left(z^{\prime \prime}, l^{\prime}\right)=1$. As exit and firing are costless, if the firm exists or fires workers, his expected marginal value from its current marginal hire will be zero.

Similarly, the surplus for the marginal worker who is matched by a hiring firm in the end-of-period state $\left(z^{\prime}, l^{\prime}\right)$ is

$$
\Pi^{\text {work }}\left(z^{\prime}, l^{\prime}\right)=\frac{1}{1+r}\left[w_{h}\left(z^{\prime}, l^{\prime}\right)+J^{e}\left(z^{\prime}, l^{\prime}\right)\right]-\frac{b+J^{o}}{1+r}
$$

where the worker enjoys $w_{h}\left(z^{\prime}, l^{\prime}\right)$ in the current period, and starts next period in a firm with the beginning-of-period state $\left(z^{\prime}, l^{\prime}\right)$. Since at the time of bargaining the vacancy posting and matching process are over, if the bargaining fails, the worker is unemployed this period and starts next period in state $o$. 
The worker and firm split the total surplus by Nash bargaining where the bargaining power of the firm is given by $\beta$, i.e.

$$
\beta \Pi^{f i r m}\left(z^{\prime}, l^{\prime}\right)=(1-\beta) \Pi^{\text {wor ker }}\left(z^{\prime}, l^{\prime}\right)
$$

Wages are thus determined as a solution to the following equation

$\beta\left[\frac{\partial \pi\left(z^{\prime}, l^{\prime}\right)}{\partial l^{\prime}}+\mathcal{I}^{c}\left(z^{\prime}, l^{\prime}\right) \int_{z^{\prime \prime}} \mathcal{I}^{h}\left(z^{\prime \prime}, l^{\prime}\right) \frac{\partial \mathcal{V}\left(z^{\prime \prime}, l^{\prime}\right)}{\partial l^{\prime}} h\left(z^{\prime \prime} \mid z^{\prime}\right) d z^{\prime \prime}\right]=(1-\beta)\left[w_{h}\left(z^{\prime}, l^{\prime}\right)+J^{e}\left(z^{\prime}, l^{\prime}\right)-\left(b+J^{o}\right)\right]$

Using equation (15) and noting that $J^{u}=J^{o}$ in equilibrium, the right hand side of (22) can be written as

$$
(1-\beta) w_{h}\left(z^{\prime}, l^{\prime}\right)+(1-\beta)\left[\mathcal{I}^{c}\left(z^{\prime}, l^{\prime}\right) \int_{z^{\prime \prime}} \widetilde{J}^{e}\left(z^{\prime \prime}, l^{\prime}\right) h\left(z^{\prime \prime} \mid z^{\prime}\right) d z^{\prime \prime}-\mathcal{I}^{c}\left(z^{\prime}, l^{\prime}\right) J^{o}-b\right]
$$

Adding and subtracting $(1-\beta) \frac{b+J^{0}}{1+r} \mathcal{I}^{c}\left(z^{\prime}, l^{\prime}\right)$ to equation (23) gives

$$
\begin{aligned}
& (1-\beta) w_{h}\left(z^{\prime}, l^{\prime}\right)+(1-\beta) \mathcal{I}^{c}\left(z^{\prime}, l^{\prime}\right)\left[\int_{z^{\prime \prime}}\left(\widetilde{J}^{e}\left(z^{\prime \prime}, l^{\prime}\right)-\frac{b+J^{o}}{1+r}\right) h\left(z^{\prime \prime} \mid z^{\prime}\right) d z^{\prime \prime}\right. \\
& +(1-\beta) \frac{b+J^{o}}{1+r} \mathcal{I}^{c}\left(z^{\prime}, l^{\prime}\right)-(1-\beta) \mathcal{I}^{c}\left(z^{\prime}, l^{\prime}\right) J^{o}-(1-\beta) b
\end{aligned}
$$

After some simple algebra, the the right hand side of (22) becomes

$$
(1-\beta) w_{h}\left(z^{\prime}, l^{\prime}\right)-(1-\beta) J_{\text {end }}^{u}\left(z^{\prime}, l^{\prime}\right)+(1-\beta) \mathcal{I}^{c}\left(z^{\prime}, l^{\prime}\right) \int_{z^{\prime \prime}}\left(\widetilde{J}^{e}\left(z^{\prime \prime}, l^{\prime}\right)-\frac{b+J^{o}}{1+r}\right) h\left(z^{\prime \prime} \mid z^{\prime}\right) d z^{\prime \prime}
$$

where

$$
J_{\text {end }}^{u}\left(z^{\prime}, l^{\prime}\right)=\mathcal{I}^{c}\left(z^{\prime}, l^{\prime}\right)\left[r\left(\frac{b+J^{o}}{1+r}\right)-b\right]+b .
$$

The term $(1-\beta) \mathcal{I}^{c}\left(z^{\prime}, l^{\prime}\right) \int_{z^{\prime \prime}}\left(\widetilde{J}^{e}\left(z^{\prime \prime}, l^{\prime}\right)-\frac{b+J^{o}}{1+r}\right) h\left(z^{\prime \prime} \mid z^{\prime}\right) d z^{\prime \prime}$ in equation (24) is simply the expected capital gain for the worker from being employed in a $\left(z^{\prime \prime}, l^{\prime}\right)$ firm at the interim stage 
next period. If the firm does not exit, the worker will enjoy the value of $\widetilde{J}^{e}\left(z^{\prime \prime}, l^{\prime}\right)$ over and above his outside option $\frac{b+J^{0}}{1+r}$. This term will cancels with $\beta \mathcal{I}^{c}\left(z^{\prime}, l^{\prime}\right) \int_{z^{\prime \prime}} \mathcal{I}^{h}\left(z^{\prime \prime}, l^{\prime}\right) \frac{\partial \mathcal{V}\left(z^{\prime \prime}, l^{\prime}\right)}{\partial l^{\prime}} h\left(z^{\prime \prime} \mid z^{\prime}\right) d z^{\prime \prime}$, which appears on the left hand side of equation (22), since the worker gets the fraction $1-\beta$ of any future capital gain while the firm gets $\beta$.

Then, equation (22) becomes

$$
\frac{\partial w_{h}\left(z^{\prime}, l^{\prime}\right)}{\partial l^{\prime}} \beta l^{\prime}+w_{h}\left(z^{\prime}, l^{\prime}\right)-\beta \frac{\partial r\left(z^{\prime}, l^{\prime}\right)}{\partial l^{\prime}}-(1-\beta) J_{e n d}^{u}\left(z^{\prime}, l^{\prime}\right)=0
$$

which is the same as Bertola and Garibaldi (2001)'s equation (10). Using

$$
\frac{\partial r\left(z^{\prime}, l^{\prime}\right)}{\partial l}=\alpha \frac{\sigma-1}{\sigma} D^{\frac{1}{\sigma}}\left(z^{\prime}\right)^{\frac{\sigma-1}{\sigma}}\left(l^{\prime}\right)^{\alpha\left(\frac{\sigma-1}{\sigma}\right)-1}
$$

the wage schedule for expanding firms is given by

$$
w_{h}\left(z^{\prime}, l^{\prime}\right)=(1-\beta) J_{\text {end }}^{u}+\Gamma(\alpha, \beta, \sigma) D^{\frac{1}{\sigma}}\left(z^{\prime}\right)^{\frac{\sigma-1}{\sigma}}\left(l^{\prime}\right)^{-\left[\frac{\alpha}{\sigma}+(1-\alpha)\right]}
$$

where $\Gamma(\alpha, \beta, \sigma)$ is a function of the parameters of the problem

$$
\Gamma(\alpha, \beta, \sigma)=\frac{\alpha \beta(\sigma-1)}{\sigma(1-\beta)+\alpha \beta(\sigma-1)} .
$$

Note that the term

$$
J_{\text {end }}^{u}\left(z^{\prime}, l^{\prime}\right)=\mathcal{I}^{c}\left(z^{\prime}, l^{\prime}\right)\left[r\left(\frac{b+J^{o}}{1+r}\right)-b\right]+b 0
$$

is worker's outside option at the time of bargaining. If the firm exist next period, i.e. $\mathcal{I}^{c}\left(z^{\prime}, l^{\prime}\right)=0, J_{\text {end }}^{u}=b$ and the worker's wage is simply its current addition to revenue plus $(1-\beta)$ of its current outside option. If $\mathcal{I}^{c}\left(z^{\prime}, l\right)=1$, however,

$$
J_{\text {end }}^{u}=r\left(\frac{b+J^{o}}{1+r}\right)
$$

which is the flow value of outside option $\frac{b+J^{o}}{1+r}$. 


\section{Firing Wages}

To derive the firing wage schedule, we begin by writing the value of employment at a firing firm in the interim stage as

$$
J_{f}^{e}\left(z^{\prime}, l\right)=\frac{1}{1+r}\left[p_{f}\left(z^{\prime}, l\right)\left((1+r) J^{u}\right)+\left(1-p_{f}\left(z^{\prime}, l\right)\right)\left(w_{f}\left(z^{\prime}, l^{\prime}\right)+J^{e}\left(z^{\prime}, l^{\prime}\right)\right)\right],
$$

where $l^{\prime}=L\left(z^{\prime}, l\right)$. This expression reflects the possibility of losing one's job, $p_{f}\left(z^{\prime}, l\right)$, which we assume occurs at firing firms with probability

$$
p_{f}\left(z^{\prime}, l\right)=\frac{l-L\left(z^{\prime} \cdot l\right)}{l}
$$

It also reflects the fact that workers who are not fired are paid just enough to retain them. Next we note that, since workers are indifferent between staying and leaving, which gives us

$$
w_{f}\left(z^{\prime}, l^{\prime}\right)+J^{e}\left(z^{\prime}, l^{\prime}\right)=(1+r) J^{u},
$$

and defines the wage schedule faced by firing firms as

$$
w_{f}\left(z^{\prime}, l^{\prime}\right)=(1+r) J^{u}-J^{e}\left(z^{\prime}, l^{\prime}\right) .
$$

Note that as a hiring firm increases its employment level toward the point at which $\Pi^{\text {firm }}\left(z^{\prime}, l^{\prime}\right)=$ 0 , the hiring wage approaches $w_{f}\left(z^{\prime}, l^{\prime}\right)$ by $(22)$. 


\section{Appendix 2: Steady State Equilibrium}

A steady state equilibrium consists of a measure of differentiated goods $N$, an exact price index for composite good $P$, an aggregate quantity index for composite good $Q$, aggregate income $I$, a measure of workforce in services $L_{s}$, a measure of unemployed workers in differentiated goods sector $L_{u}$, unemployment rate in differentiated goods sector $\mu_{u}$, job finding rate $\phi_{w}$, vacancy filling rate $\phi_{f}$, the exit rate $\mu_{x}$, the measure of entrants $M$; the value functions and associated policy functions $\mathcal{V}(z, l), L(z, l), \mathcal{I}^{h}(z, l), \mathcal{I}^{c}\left(z_{-1}, l\right), J^{o}, J^{u}, J^{s}$, and $J^{e}$; the wage schedules $w_{h}(z, l)$ and $w_{f}(z, l)$, and end-of-the period and interim distributions $f(z, l)$ and $\widetilde{f}(z, l)$ such that

1. Steady State Distributions: Because of the transitions that occur within a period, we have to distinguish the distributions at different points in time. Let $f(z, l)$ and $\widetilde{f}(z, l)$ be the stationary probability distributions over $(z, l)$ at the end and interim states, respectively. In equilibrium, these distributions reproduce themselves through the Markov processes on $z$, the policy functions and the productivity draws upon entry. The interim distribution is defined as

$$
\widetilde{f}(z, l)=\left\{\begin{array}{l}
=\int_{\widehat{z}} h(z \mid \widehat{z}) f(\widehat{z}, l) I^{c}(\widehat{z}, l) d \widehat{z} \text { if } l \neq l_{e} \\
=f_{e}(z) \text { if } l=l_{e}
\end{array}\right.
$$

In turn, the end-of-the period distribution is

$$
f\left(z, l^{\prime}\right)=\int_{\widehat{l}} \tilde{f}(z, \widehat{l}) I_{(L(z, \widehat{l}), l)},
$$

where $I_{(L(z, \widehat{l}), l)}$ is an indicator function with $I_{(L(z, \widehat{l}), l)}=1$ if $L(z, \widehat{l})=l$.

2. Market Clearance in Sector $S$ : Demand for the $S$-sector comes from two sources: consumers spend a $(1-\gamma)$ fraction of aggregate income $I$ on it, and firms demand it to 
pay their fixed operation costs, labor adjustment and entry costs. Define the fraction of hiring firms as $\mu_{h}=\int_{z} \int_{l} \mathcal{I}^{h}(z, l) \widetilde{f}(z, l) d l d z$. Average labor adjustment cost is given by

$$
\widetilde{c}=\int_{z} \int_{l} C\left(l, L(z, l) \mathcal{I}^{h}(z, l) \frac{\widetilde{f}(z, l)}{\mu_{h}} d l d z .\right.
$$

Market clearance condition in this sector is

$$
L_{S}+b \mu_{u} L_{Q}=(1-\gamma) I+N\left(\widetilde{c}+c_{f}\right)+M c_{e},
$$

where $L_{S}$ and $L_{Q}$ are the size of the workforce in the two sectors, and $\mu_{u}$ is the unemployment level within the $Q$-sector.

3. Labor Market: With a normalized measure of workers, the size of the workforce in the $Q$-sector is $L_{Q}=1-L_{S}$. Total production employment in the differentiated good sector is given by

$$
E_{Q}=N \int_{z} \int_{l} l f(z, l) d l d z=\left(1-\mu_{u}\right) L_{Q} .
$$

The measure of unemployed workers is then

$$
L_{u}=L_{Q}-E_{Q}=\mu_{u} L_{Q} .
$$

The equilibrium condition for the labor market in the $Q$-sector is that flows out of employment equal the flows into employment. Every period, a fraction $k$ of workers in that sector are laid off due to exits and downsizing. The equilibrium flow condition is

$$
\mu_{u} L_{Q} \phi^{w}=\left(1-\mu_{u}\right) L_{Q} k,
$$

which yields the usual Beveridge curve

$$
\mu_{u}=\frac{k}{k+\phi^{w}}
$$


Aggregate number of vacancies in this economy is

$$
V=N \int_{z} \int_{l} v(z, l) \mathcal{I}^{h}(z, l) \frac{\tilde{f}(z, l)}{\mu_{h}} d l d z .
$$

which, together with $L_{u}$, determines matching probabilities $\phi^{f}\left(V, L_{u}\right)$ and $\phi^{w}\left(V, L_{u}\right)$ that firms and workers take as given.

4. Firm turnover: In equilibrium, there is a positive mass of entry $M$ every period so that the free entry condition (8) holds with equality. The fraction of firms exiting is implied by the steady state distribution and the exit policy function,

$$
\mu_{\text {exit }}=\int_{z} \int_{l}\left[1-\mathcal{I}^{c}(z, l)\right] f(z, l) d l d z
$$

and measure of exits equals that of entrants,

$$
M=\mu_{\text {exit }} N .
$$

5. Income and Market Clearance for the $Q$-sector: The composite good $Q$ and its price are given by:

$$
P=\left(N \int_{z} \int_{l} p(z, l)^{1-\sigma} f(z, l) d l d z\right)^{\frac{1}{1-\sigma}}
$$

and

$$
Q=\left(N \int_{z} \int_{l} q(z, l)^{\frac{\sigma-1}{\sigma}} f(z, l) d l d z\right)^{\frac{\sigma}{\sigma-1}}
$$

Aggregating over the revenue functions (4) across producers, total revenues earned by the differentiated good sector is a fraction $\gamma$ of total income in the economy:

$$
\gamma I=P Q=R .
$$


By Walras' Law, market clearance in the labor market and the $S$-sector implies the clearance of the $Q$-sector. We show that by writing aggregate income in the closed economy:

$$
I=L_{S}+b \mu_{u} L_{Q}+W_{Q}+\Pi
$$

where $L_{S}$ is employment (and income earned) in the $S$-sector and $\mu_{u} L_{Q} b$ is the income earned by the unemployed through home production. Let $\widetilde{\mathcal{I}}^{h}(z, l)$ be an indicator function which equals one if a firm in state $(z, l)$ at the end of a period achieved this state by hiring in the interim. $\Pi$ is total profits net of entry, vacancy and firing costs,

$$
\begin{aligned}
\Pi= & N \int_{z} \int_{l}\left[\widetilde{\mathcal{I}}^{h}(z, l)\left\{r(z, l)-w_{h}(z, l) l\right\}\right. \\
& \left.+\left[1-\widetilde{\mathcal{I}}^{h}(z, l)\right]\left\{r(z, l)-w_{f}(z, l) l\right\}\right] f(z, l) d l d z \\
& -N \widetilde{c}-N c_{f}-M c_{e}
\end{aligned}
$$

and $W_{Q}$ is the total wage bill in the $Q$-sector

$$
W_{Q}=N \int_{z} \int_{l}\left\{\widetilde{\mathcal{I}}^{h}(z, l) w_{h}(z, l) \cdot l+\left[1-\widetilde{\mathcal{I}}^{h}(z, l)\right] w_{f}(z, l) l\right\} f(z, l) d l d z .
$$

Using (25), (26) and (27),

$$
\gamma I=N \int_{z} \int_{l}\left[\widetilde{\mathcal{I}}^{h}(z, l) r(z, l)+\left[1-\widetilde{\mathcal{I}}^{h}(z, l)\right] r(z, l)\right] f(z, l) d l d z
$$

Right-hand of that equation is total revenue $R$ earned by the differentiated good sector.

6. Workers are indifferent between taking a certain job in the undifferentiated sector and searching a job in industrial sector.

$$
J^{o}=J^{s}=J^{u} .
$$




\section{Appendix 3: Open Economy Equilibrium}

\section{Equilibrium conditions}

The equilibrium definition in an open economy is similar to that in a closed economy with the

addition of an export policy function $\mathcal{I}_{\eta>0}^{x}(z, l)$, the exchange rate $\varepsilon_{x}$, the fraction of firms exporting $\mu_{x}$ and the trade balance condition. Here we show that when all markets clear, trade balance condition follows from Walras' Law.

By definition of income as before,

$$
\begin{aligned}
& I=L_{s}+b\left(u L_{Q}\right)+W_{Q}+\Pi+T_{m} \\
& I=L_{s}+b\left(u L_{Q}\right)+W_{Q}+R_{x}+R_{d}-W_{Q}-N \widetilde{c}-N c_{f}-M c_{e}+T_{m}
\end{aligned}
$$

where $N \widetilde{c}, N c_{f}$ and $M c_{e}$ are aggregate hiring costs, overhead and entry costs respectively. Market clearance for $S$ sector is

$$
L_{S}+b\left(u L_{Q}\right)=(1-\gamma) I+N \widetilde{c}+N c_{f}+M c_{e}
$$

which implies

$$
\gamma I=R_{x}+R_{d}+T_{m}
$$

On the expenditure side, a fraction $\gamma$ of income is spent on differentiated goods, foreign and domestic.

$$
\gamma I=E_{m}+E_{d} .
$$

By domestic market clearance, $E_{d}=E_{m}$ which implies

$$
R_{x}+T_{m}=E_{m} .
$$


Payment to foreigners is given by $R_{m}=E_{m} /\left(1+\tau_{m}\right)$. Substituting $E_{m}$ and cancelling tariff revenues $T_{m}=R_{m} \tau_{m}$ leaves us with the trade balance condition:

$$
R_{m}=R_{x}
$$

\section{Price and quantity indices}

To re-state the price and quantity indices for the open economy case, let $N$ now denote total varieties sold in each country, let $N_{D}$ denote the number of varieties that each country produces domestically, and let $\mu_{x}$ be the equilibrium fraction of firms in each country that export. (By symmetry, $N=\left(1+\mu_{x}\right) N_{D}$.) Then, the composite good $Q$ is the following weighted average of foreign and domestic quantities:

$$
Q=N^{\frac{\sigma}{\sigma-1}}\left(\frac{\mu_{x}}{1+\mu_{x}} Q_{F}^{\frac{\sigma-1}{\sigma}}+\frac{1}{1+\mu_{x}} Q_{D}^{\frac{\sigma-1}{\sigma}}\right)^{\frac{\sigma}{\sigma-1}}
$$

where

$$
Q_{F}=\left(\int_{z} \int_{l_{e}}^{\infty}\left[\frac{\eta^{*}}{\tau} z l^{\alpha}\right]^{\frac{\sigma-1}{\sigma}} \mathcal{I}_{\eta>0}^{x}(z, l) \frac{f(z, l)}{\mu_{x}} d l d z\right)^{\frac{\sigma}{\sigma-1}}
$$

and

$$
Q_{D}=\left(\mu_{x} Q_{D, x}^{\frac{\sigma-1}{\sigma}}+\left(1-\mu_{x}\right) Q_{D, n x}^{\frac{\sigma-1}{\sigma}}\right)^{\frac{\sigma}{\sigma-1}} .
$$

Also the domestic index $Q_{D}$ is itself an aggregate across domestic sales of exporters given by $Q_{D, x}$ and sales of domestic only producers represented by $Q_{D, n x}$ :

$$
Q_{D, x}=\left(\int_{z} \int_{l_{e}}^{\infty}\left[\left(1-\eta^{*}\right) z l^{\alpha}\right]^{\frac{\sigma-1}{\sigma}} \mathcal{I}^{x}(z, l) \frac{f(z, l)}{\mu_{x}} d l d z\right)^{\frac{\sigma}{\sigma-1}}
$$

and

$$
Q_{D, n x}=\left(\int_{z} \int_{l_{e}}^{\infty}\left(z l^{\alpha}\right)^{\frac{\sigma-1}{\sigma}}\left[1-\mathcal{I}^{x}(z, l)\right] \frac{f(z, l)}{1-\mu_{x}} d l d z\right)^{\frac{\sigma}{\sigma-1}}
$$


The price index for $Q$ follows from a similar aggregation. The export indicator function $\mathcal{I}^{x}(z, l)$ and the fraction of exporting firms $\mu_{x}$ are additions to the equilibrium definition in the open economy case. All conditions in the closed economy equilibrium are valid with the additional demand for the homogenous good resulting from fixed exporting $\operatorname{costs} \mu_{x} N_{D} f_{x}$ and the modified aggregate profit function to account for export revenues and costs. 


\section{Appendix 4: Estimating the Revenue Function and Productivity Process}

\section{The Revenue Function}

The equation we wish to estimate is:

$$
\begin{aligned}
\ln r_{i t}= & \rho \ln r_{i t-1}+\left(d_{H}+\mathcal{I}_{i t}^{x} \cdot d_{F}\right)-\rho\left(d_{H}+\mathcal{I}_{i t-1}^{x} \cdot d_{F}\right) \\
& +\alpha\left(\frac{\sigma-1}{\sigma}\right) \ln l_{i t}-\alpha \rho\left(\frac{\sigma-1}{\sigma}\right) \ln l_{i t-1}+\left(\frac{\sigma-1}{\sigma}\right) \epsilon_{i t} .
\end{aligned}
$$

But selection bias and simultaneity bias prevent us from consistently estimating this expression with ordinary least squares. The former problem occurs because firms choose whether to shut down partly on the basis of their $\epsilon_{i t}$ realizations, and the latter problem occurs because firms' current exporting decisions $\left(\mathcal{I}_{i t}^{x}\right)$ and employment levels $\left(l_{i t}\right)$ depend upon their current productivity levels.

\section{Selection Bias and Identification}

To deal with these problems, let $\mathcal{I}_{i t}^{c}$ be an indicator variable that takes a value of 1 if the $i^{\text {th }}$ firm continues to operate in period $t$, and 0 otherwise. Then, defining $\xi_{i t}=\epsilon_{i t}-$ $E\left[\epsilon_{i t} \mid \mathcal{I}_{i t}^{c}=1, \ln r_{i t-1}, \ln \ell_{i t-1}, \mathcal{I}_{i t-1}^{x}\right]$, the revenue function can be re-formulated as:

$$
\begin{aligned}
\ln r_{i t}= & \rho \ln r_{i t-1}+d_{H}(1-\rho)+d_{F}\left(I_{i t}^{x}-\rho \cdot I_{i t-1}^{x}\right)+\alpha \frac{\sigma-1}{\sigma} \ln \ell_{i t} \\
& -\alpha \rho \frac{\sigma-1}{\sigma} \ln \ell_{i t-1}+\frac{\sigma-1}{\sigma} E\left[\epsilon_{i t} \mid \mathcal{I}_{i t}^{c}=1, \ldots\right]+\frac{\sigma-1}{\sigma} \xi_{i t}
\end{aligned}
$$

where the error term $\xi_{i t}$ has zero mean and is orthogonal to $\ln r_{i t-1}, \ln \ell_{i t-1}, \mathcal{I}_{i t-1}^{x}$, and $E\left[\epsilon_{i t} \mid \mathcal{I}_{i t}^{c}=1, \ldots\right]$. Also, although it is correlated with current exporting decisions $\left(I_{i t}^{x}\right), \xi_{i t}$ 
is orthogonal to $E\left[\mathcal{I}_{i t}^{x} \mid \mathcal{I}_{i t}^{c}=1, \ln r_{i t-1}, \ln \ell_{i t-1}, \mathcal{I}_{i t-1}^{x}\right]$. These implications of our model can be used as the basis for a generalized method of moments (GMM) estimator that identifies the parameters of equation (A3.1). ${ }^{19}$ And the efficiency of this estimator can be improved by exploiting the moment condition $E\left(\mathcal{I}_{i t}^{x}\left(1-e^{-d_{F}}\right)-x_{i t}\right)=0$, where $\mathcal{I}_{i t}^{x}\left(1-e^{-d_{F}}\right)$ is the share of exports in total sales implied by our model and $x_{i t}$ is the observed ratio of export revenues to total sales (which we treat as a noisy measure of true export intensity).

This estimation strategy requires that we calculate $E\left[\epsilon_{i t} \mid \mathcal{I}_{i t}^{c}=1, \ln r_{i t-1}, \ln \ell_{i t-1}, \mathcal{I}_{i t-1}^{x}\right]$. To this end, recall that there is a threshold productivity level above which all firms with beginning-of-period employment level $\ell_{i t-1}$ will continue operating. Denoting this threshold productivity level $g^{*}\left(\ell_{i t-1}\right)$, the continuation condition is $z_{i t}=\rho z_{i t-1}+\epsilon_{i t}>g^{*}\left(\ell_{i t-1}\right)$. Or, since $z_{i t-1}=\frac{\sigma}{\sigma-1}\left[\ln r_{i t-1}-\left(d_{H}+\mathcal{I}_{i t-1}^{x} d_{F}\right)\right]-\alpha \ln l_{i t-1}$ (by equation 19), continuation occurs when $\frac{\epsilon_{i t}}{\sigma_{\epsilon}}>\frac{g^{*}\left(\ell_{i t-1}\right)-\rho z_{i t-1}}{\sigma_{\epsilon}} \stackrel{\text { def }}{=} g\left(r_{i t-1}, l_{i t-1}, \mathcal{I}_{i t-1}^{x}\right)$, and the probability of continuation can be calculated as

$$
p_{i t}^{C}=1-\Phi\left[g\left(\ln r_{i t-1}, \ln l_{i t-1}, \mathcal{I}_{i t-1}^{x}\right)\right]
$$

where $\epsilon_{i t} \sim N\left(0, \sigma_{\epsilon}^{2}\right)$ and $\Phi()$ is the standard normal cumulative distribution. Treating $g(\cdot)$ as a flexible function of its arguments, it follows that $p_{i t}^{C}$ values can be imputed from estimates of the probit function (A3.3), and the object of interest can be calculated using well-known properties of the normal distribution (e.g., Maddala, 1983): ${ }^{20}$

\footnotetext{
${ }^{19}$ Identification further requires that these conditional expectations be non-linear functions of their arguments and/or that they condition on additional arguments that do not appear in equation (A3.2). Note that the dependence of $\ln \ell_{i t}$ on $\epsilon_{i t}$ does not prevent us from obtaining consistent estimates of these parameters because the coefficient on $\ln \ell_{i t}$ can be inferred from the coefficients on $\ln \ell_{i t-1}$ and $\ln r_{i t-1}$.

${ }^{20}$ When estimating this probit, we use a flexible (translog) functional form for $g\left(r_{i t-1}, l_{i t-1}, I_{i t-1}^{X}\right)$.
} 


$$
\begin{aligned}
E\left[\epsilon_{i t} \mid \mathcal{I}_{i t}^{c}\right. & \left.=1, \ln r_{i t-1}, \ln \ell_{i t-1}, \mathcal{I}_{i t-1}^{x}\right]=\sigma_{\epsilon} \cdot M_{i t}, \\
\operatorname{var}\left[\epsilon_{i t} \mid \mathcal{I}_{i t}^{c}\right. & \left.=1, \ln r_{i t-1}, \ln \ell_{i t-1}, \mathcal{I}_{i t-1}^{x}\right]=\sigma_{\epsilon}^{2} \cdot\left(1-M_{i t}\left[M_{i t}-\Phi^{-1}\left(p_{i t}^{C}\right)\right]\right),
\end{aligned}
$$

where $M_{i t}=\frac{\phi\left(\Phi^{-1}\left(p_{i t}^{C}\right)\right)}{p_{i t}^{C}}$ is the relevant Mills ratio and $\phi()=\Phi^{\prime}()$.

Our estimation strategy also requires that we calculate $E\left[\mathcal{I}_{i t}^{x} \mid \mathcal{I}_{i t}^{c}=1, \ln r_{i t-1}, \ln \ell_{i t-1}, \mathcal{I}_{i t-1}^{x}\right]$. For this, note that equation (18) implies firms above some threshold productivity level will choose to export, given $\left(l_{i t-1}, z_{i t-1}\right)$. Thus, once again exploiting the normality of $\epsilon_{i t}$, we can write

$$
E\left[\mathcal{I}_{i t}^{x} \mid \mathcal{I}_{i t}^{c}=1, \ln r_{i t-1}, \ln \ell_{i t-1}, \mathcal{I}_{i t-1}^{x}\right]=p_{i t}^{X}=1-\Phi\left[h\left(\ln r_{i t-1}, \ln l_{i t-1}, \mathcal{I}_{i t-1}^{x}\right)\right]
$$

where $p_{i t}^{X}$ is the probability that firm $i$ exports in period $t$ and $h\left(r_{i t-1}, l_{i t-1}, \mathcal{I}_{i t-1}^{x}\right)$ is a flexible function of its arguments. ${ }^{21}$ Hence $E\left[\mathcal{I}_{i t}^{x} \mid \mathcal{I}_{i t}^{c}=1, \ldots\right]$ can be calculated by estimating the probit (A3.4) and retrieving the imputed $p_{i t}^{X}$ values. Clearly, identification here comes from the non-linear form of the probit function. ${ }^{22}$

\section{The Moment Conditions}

To summarize, our GMM estimator is based on the moment conditions:

$$
\begin{aligned}
E\left[\xi_{i t} \ln r_{i t-1}\right] & =0, E\left[\xi_{i t} \ln \ell_{i t-1}\right]=0, E\left[\xi_{i t} M_{i t}\right]=0, E\left[\xi_{i t} \mathcal{I}_{i t-1}^{x}\right]=0, \\
E\left[\xi_{i t} p_{i t}^{X}\right] & =0, E\left[\xi_{i t}\right]=0, E\left[\nu_{i t}^{\epsilon}\right]=0, E\left[\nu_{i t}^{x}\right]=0 .
\end{aligned}
$$

\footnotetext{
${ }^{21}$ It is interesting that lagged exports help predict current exports here, even though we have assumed away sunk entry costs. The reason is that, by (19), lagged exports help to explain lagged productivity.

${ }^{22}$ Olley and Pakes (1996) develop a related strategy that posits a determinstic linkage between productivity shocks and investment levels. This allows them to get away from functional form as a basis for identification, but it is not an available option in the present setting.
} 
where:

$$
\begin{aligned}
\xi_{i t} & =\frac{\sigma}{\sigma-1}\left[\ln r_{i t}-d_{H}(1-\rho)-d_{F}\left(\mathcal{I}_{i t}^{x}-\rho \mathcal{I}_{i t-1}^{x}\right)-\rho \ln r_{i t-1}\right]+\alpha \rho \ln \ell_{i t-1}-\alpha \ln \ell_{i t}-\sigma_{\epsilon} \cdot M_{i t}, \\
\nu_{i t}^{\epsilon} & =\xi_{i t}^{2}-\sigma_{\epsilon}^{2} \cdot\left(1-M_{i t}\left[M_{i t}-\Phi^{-1}\left(p_{i t}\right)\right]\right), \\
\nu_{i t}^{x} & =\mathcal{I}_{i t}^{x}\left(1-e^{-d_{X}}\right)-x_{i t} .
\end{aligned}
$$

In principle, these conditions identify $\rho, \alpha, \sigma_{\epsilon}^{2}, d_{X}, d_{H}, \frac{\sigma-1}{\sigma}$. In practice, while $\rho, \alpha, \sigma_{\epsilon}^{2}, d_{X}$, and $d_{H}$ can be estimated with some precision using this estimator, $\frac{\sigma-1}{\sigma}$ is poorly identified. We therefore fix $\frac{\sigma-1}{\sigma}$ at several alternative values taken from the existing literature, and generate corresponding sets of estimates for the remaining parameters. (Refer to Table 1 in the text.) Our results proved not to be sensitive to the inclusion of time dummies in A1.1. Accordingly, since our theoretical model presumes that the macro environment is stable, we focus our attention on the case in which they are omitted. 


\section{Appendix 5: Numerical Solution Algorithm}

In order to solve the model numerically, we discretize the productivity space using the method suggested by Tauchen (1986) and uniformly discretize the employment space between $\left[l_{e}, \bar{L}\right]$. We make sure that the arbitrarily imposed upper bound $\bar{L}$ is not binding by checking firms' hiring policy functions. The following steps, where consecutively numbered items are loops nested in each other, describe the solution algorithm.

1. Bisection over job filling probability $\phi_{f}$ : Take a lower bound $\underline{\phi}_{f}$ and an upper bound $\bar{\phi}_{f}$ in $[0,1]$. Let $\phi_{f}=\left(\underline{\phi}_{f}+\bar{\phi}_{f}\right) / 2$. When the nested loops are solved, we obtain a value for $E J_{h}^{e}$, and we can calculate the implied $\phi_{w}$ using the definition of the matching function. Calculate the value of unemployment, $J^{u}$, by (10). Update either $\bar{\phi}_{f}$ or $\underline{\phi}_{f}$ depending on $J^{u} \lessgtr J^{o}$. Iterate until workers' indifference condition for sectoral choice holds approximately, that is, until $J^{u}$ is sufficiently close to $J^{o}$.

2. Bisection over share of output exported $\eta$ : Taking $\phi_{f}$ as given, take a lower bound $\underline{\eta}$ and an upper bound $\bar{\eta}$ in $[0,1]$. Let $\eta=(\underline{\eta}+\bar{\eta}) / 2$. Iterate until trade balance holds approximately.

3. Iteration over firing wage schedule $w_{f}(z, l)$ : Start with some initial wage schedule $w_{f}^{j}(z, l)$. Taking $\left(\phi_{f}, \eta\right)$ as given, the nested loops solve for the value of employment in a firm, $J^{e}(z, l)$. Update the wage schedule $w_{f}^{j+1}(z, l)$ using expression (16), imposing the equilibrium condition $J^{u}=1 / r$. Iterate until $w_{f}^{j+1}(z, l)$ is sufficiently close to $w_{f}^{j}(z, l)$.

4. Bisection over demand level $D_{H}$ : Start with lower and upper bounds $\left(\underline{D}_{H}, \bar{D}_{H}\right)$ and let 
$D_{H}=\left(\underline{D}_{H}+\bar{D}_{H}\right) / 2$. Solve for firms' problem to get policy functions for exit, hiring and exporting. Find the value of entry, $\mathcal{V}_{e}$, and update either $\underline{D}_{H}$ or $\bar{D}_{H}$ depending on $\mathcal{V}_{e} \lessgtr c_{e}$. Iterate until free entry condition holds approximately such that $\mathcal{V}_{e}$ is sufficiently close to the cost of entry, $c_{e}$.

To find the value of matching with a hiring firm conditional on the event of matching occurring, $E J_{h}^{e}$, we first derive the steady state distribution $f(z, l)$ as the fixed point of a contraction using the policy functions of the firm, the stochastic shocks $h\left(z^{\prime} \mid z\right)$ and productivity draws of the entrants. Using the vacancy posting policy of the firm, we then find the job offer distribution $g(z, l)$ as in the text and obtain $E J_{h}^{e}$ by $(14)$.

The above algorithm solves the model for a given set of exogenous parameter values, including the cost of entry $c_{e}$. When we calibrate the model to obtain estimates of some of these parameters, we treat the set of data moments as one particular general equilibrium outcome. Thus in the modified algorithm employed for calibration, we use the empirical value of $\eta$. We also take the value of $D_{H}$ estimated in the first stage as given and set $c_{e}$ such that free entry holds. This enables us to skip loops 2 and 4 in the calibration. When we do policy experiments by varying the parameters related to trade costs, the values of $D_{H}$ and $\eta$ change endogenously, so we use the complete algorithm to solve the model. 


\section{References}

[1] Abowd, J., F. Kramatz and D. Margolis (1999). "High Wage Workers and High Wage Firms," Econometrica, Vol. 67, No. 2, 251-333.

[2] Abowd, John, Robert Creecy and Francis Kramarz. 2002. "Computing Person and Firm Effects Using Linked Longitudinal Employer-Employee Data," Working Paper, Cornell University.

[3] Albrecht, J. and S. Vroman. (2002) "A Matching Model with Endogenous Skill Requirements" International Economic Review, 43: 238-305.

[4] Amiti, Mary and Donald R. Davis (2008). "Trade, Firms, and Wages: Theory and Evidence," NBER Working Papers 14106.

[5] Artuc, Erhan, Chaudhuri, Shubham and McLaren, John (2007) "Trade Shocks and Labor Adjustment: A Structural Empirical Approach" NBER Working Paper No. W13465.

[6] Atekson, Andrew and Ariel Burstein (forthcoming) "Pricing-to-Market, Trade Costs, and International Relative Prices," American Economic Review.

[7] Attanasio, Orazio, Golberg, Pinelopi K. and Nina Pavcnik (2004) "Trade Reforms and Wage Inequality in Colombia", Journal of Development Economics, 74, August 2004, pp. $331-366$

[8] Bernard, Andrew B. and J. Bradford Jensen, 1999. "Exceptional exporter performance: Cause, Effect, or both?" Journal of International Economics, 47(1): 1-25. 
[9] Bertola, Giuseppe and Ricardo Caballero (1994) "Cross-sectional Efficiency and Labour Hoarding in a Matching Model of Unemployment," Review of Economic Studies 61, 43547.

[10] Bertola, Giuseppe and Pietro Garibaldi (2001) "Wages and the Size of Firms in Dynamic Matching Models," Review of Economic Dynamics 4, 335-368.

[11] Bond, Eric, Tybout James and Hale Utar (2008). "Credit Rationing, Macro Volatility, and Industrial Evolution in Developing Countries," mimeo.

[12] Cahuc, Pierre, Etienne Wasmer (2001). "Does Intrafirm Bargaining Matter in Large Firm Matching Model?" Macroeconomic Dynamics, Volume 5, Issue 05, pp 742-747.

[13] Cooper, Russell, John Haltiwanger, and Jonathan Willis (2007). "Search Frictions: Matching Aggregate and Establishment Observations," Journal of Monetary Economics 54, pp. 56-78.

[14] Cunat, Alejandro and Marc J. Melitz (2007). "Volatility, Labor Market Flexibility, and the Pattern of Comparative Advantage," NBER Working Papers 13062.

[15] Das, Mita, Roberts, Mark and James Tybout (2007) "Market Entry Costs, Producer Heterogeneity and Export Dynamics," Econometrica, 75 (3), 837-873.

[16] Davidson C., S. Matusz and A. Shevchenko (2006) "Globalization and Firm-Level Adjustment with Imperfect Labor Markets," Working Paper, Michigan State University.

[17] Davidson, C., L. Martin, and S. Matusz (1999) "Trade and search generated unemployment," Journal of International Economics 48(2), pp. 271-299. 
[18] Davis, Donald R. and James Harrigan (2007). "Good Jobs, Bad Jobs, and Trade Liberalization," NBER Working Papers 13139.

[19] Davis, S., J. Haltiwanger, and S. Shuh (1998). Job Creation and Destruction (MIT Press).

[20] Demidova, S., and Rodríguez-Clare (2008). "Trade Policy under Firm-Level Heterogeneity in a Small Economy," Working Paper, Pennsylvania State University.

[21] den Haan, Wouter J., Garey Ramey and Joel Watson (2000). "Job Destruction and the Propagation of Shocks," American Economic Review, 90, 482-98.

[22] De Loecker, Jan and Frederick Warzynski (2009). "Markups and Firm-Level Export Status," Working Paper, Department of Economics, Princeton University.

[23] Eaton, Jonathan, Marcela Eslava, Maurice Kugler and James Tybout (2007). "The Margins of Entry into Export Markets: Evidence from Colombia," forthcoming in The Organization of Firms in a Global Economy, edited by Elhanan Helpman, Dalia Marin, and Thierry Verdier (Harvard University Press).

[24] Egger, Hartmut and Udo Kreickemeier (2007). "Firm Heterogeneity and the Labour Market Effects of Trade Liberalisation," CESifo Working Paper Series CESifo Working Paper No.2000.

[25] Feenstra, Robert C., Lipsey, Robert E., Deng, Haiyan, Ma, Alyson C. and Hengyong Mo (2005) "World Trade Flows: 1962-2000" NBER Working Paper 11040.

[26] Felbermayr, Gabriel, Prat, Julien, and Hans-Jorg Schmerer (2007) "Melitz meets Pissarides: Firm heterogeneity, search unemployment and trade liberalization", mimeo. 
[27] Goldberg, PK, Pavcnik, N, 2007, "Distributional Effects of Globalization in Developing Countries," Journal of Economic Literature XLV: 39-82.

[28] Hallak, Juan Carlos and Jagadish Sividasan (2008). "Productivity, Quality, and Exporting Behavior Under Minimum Quality Requirement," Working Paper, The University of Michigan.

[29] Haltiwanger, John, Adriana Kugler, Maurice Kugler, Alejandro Micco, and Carmen Pages, "Effects of Tariffs and Real Exchange Rates on Job Reallocation: Evidence from Latin America," Journal of Policy Reform, Special Issue December 2004, 7 (4), 191-208.

[30] Harris, J. and M. Todaro (1970) "Migration, Unemployment, and Development: A TwoSector Analysis," American Economic Review 60: 126-142.

[31] Helpman, Elhanan and Oleg Itskhoki (2007) "Labor Market Rigidities, Trade and Unemployment," Working Paper, Harvard University.

[32] Helpman, Elhanan, Itskhoki , Oleg and Stephen Redding (2008). "Wages, Unemployment and Inequality with Heterogeneous Firms and Workers", Working Paper, Harvard University.

[33] Hobijn, Bart and Aysegul Sahin (2007), "Firms and Flexibility," Working Paper, Federal Reserve Bank of New York,

[34] Hopenhayn, Hugo (1992), "Entry, Exit, and Firm Dynamics in Long Run Equilibrium," Econometrica, 60(5): 1127-1150. 
[35] Hopenhayn, H. and Rogerson, R. (1993). Job Turnover and Policy Evaluation: A General Equilibrium Analysis. Journal of Political Economy, 101 (5), 915-938.

[36] Inter-American Development Bank (2004). Good Job Wanted: Labor Markets in Latin America. Economic and Social Progress Report, Published by the Inter-American Development Bank, Distributed by The Johns Hopkins University Press, Washington, D.C.

[37] Kambourov, G. (2006). "Labor Market Restrictions and the Sectoral Reallocation of Workers: The Case of Trade Liberalizations," University of Toronto.

[38] Koeniger, W. and Prat, J. (2007). "Employment Protection, Product Market Regulation and Firm Selection," The Economic Journal, 117 (521), F302-F332.

[39] Kugler, Maurice and Eric Verhoogen (2008). "The Quality-Complementarity Hypothesis: Theory and New Evidence from Colombia," Working Paper, Columbia University, Department of Economics.

[40] Lentz, Rasmus and Mortensen, Dale T. (2008) "Labor Market Frictions, Firm Heterogeneity, and Aggregate Employment and Productivity," mimeo.

[41] Melitz, Marc (2003) "The Impact of Trade on Intra-Industry Reallocations and Aggregate Industry Productivity," Econometrica 71, 1695-1725.

[42] Meltiz, Marc and Gianmarco Ottaviano (2008). "Market Size, Trade and Producitivty," Review of Economic Studies 75(1): 295-316.

[43] Menezes-Filho, Naercio Aquino and Marc-Andreas Muendler. 2007. "Labor Reallocation in Response to Trade Reform," Working Paper, University of California, San Diego 
[44] Olley, G. Steven and Ariel Pakes. (1996). The Dynamics of Productivity in the Telecommunications Equipment Industry. Econometrica 64, 1263-98.

[45] Pissarides, Christopher A. (2000). Equilibrium Unemployment Theory,second edition, Cambridge, MA: MIT Press.

[46] Roberts, M. (1996) "Employment Flows and Producer Turnover" in M. Roberts and J. Tybout, eds., Industrial Evolution in Developing Countries (Oxford University Press).

[47] Rodrik, Dani (1997). Has Globalization Gone too Far?, Washington, D.C.: Institute for International Economics.

[48] Rogerson, R.; Shimer, R. and Wright, R. (2005). "Search-Theoretic Models of the Labor Market." Journal of Economic Literature, 43(4): 959-988. Also NBER Working Paper 10655, http://www.nber.org/papers/w10655.

[49] Stole, Lars A. and Jeffrey Zwiebel (1996) "Intra-Firm Bargaining under Non-Binding Contracts." The Review of Economic Studies, 63(3), pp. 375-410.

[50] Utar, Hale (2008). "Import Competition and Employment Dynamics," Working Paper, Department of Economics, University of Colorado.

[51] Veracierto, M. (2001), 'Employment Flows, Capital Mobility, and Policy Analysis', International Economic Review 42(3), 571-595. 33.

[52] World Bank (2008), Global Purchasing Power Parities and Real Expenditures, 2005 International Comparison Program, World Bank, Washington D.C. 
[53] Yeaple, S. (2005) "A Simple Model of Firm Heterogeneity, International Trade, and Wages," Journal of International Economics 65(1), pp. 1-20. 